Check for updates

Cite this: New J. Chem., 2021 45,6640

Received 28th January 2021 Accepted 19th March 2021

DOI: 10.1039/d1nj00456e

rsc.li/njc

\section{Nonlinear optical properties of diaromatic stilbene, butadiene and thiophene derivatives $\dagger$}

\author{
Esa Kukkonen, (D) a Elmeri Lahtinen, (D) a Pasi Myllyperkiö, (D) ${ }^{b}$ Matti Haukka (D) a and \\ Jari Konu (iD *a
}

\begin{abstract}
Series of highly polar stilbene (1a-e), diphenylbutadiene $(\mathbf{2} \mathbf{a}-\mathbf{c})$ and phenylethenylthiophene $(\mathbf{3 a}-\mathbf{c})$ derivatives were prepared via Horner-Wadsworth-Emmons method with a view to produce new and efficient materials for second harmonic generation (SHG) in the solid-state. The single-crystal X-ray structures of compounds 1-3 reveal extensive polymorphism and a peculiar photodimerization of the 2-chloro-3,4-dimethoxy-4'nitrostilbene derivative $1 \mathrm{a}$ to afford two polymorphs of tetra-aryl cyclobutane 4 . The stilbene congeners 2-chloro-3,4-dimethoxy-4'-nitrostilbene (1a-non-centro), 5-bromo-2-hydroxy-3-nitro-4'-nitrostilbene (1b) and 4-dimethylamino-4'-nitrostilbene (1e), as well as 4'-fluoro-4" -nitro-1,4-diphenyl-1,3-butadiene (2a) present the ideal, non-centrosymmetric arrangement of the chromophores for nonlinear optical (NLO) activity. Compounds $\mathbf{1 b}$ and $\mathbf{2 a}$ exhibit only relatively low intensity for second harmonic generation (0.04 and 0.18 times that of urea reference, respectively), while the stilbene polymorph $1 \mathrm{a} \cdot \mathrm{non}$-centro shows NLO activity of over 32 times that of urea. In addition, the conjugated diaromatic compounds 1-3 display fluorescence behaviour in $\mathrm{CH}_{2} \mathrm{Cl}_{2}$ solutions with the exception of stilbene derivative $\mathbf{1} \mathbf{b}$.
\end{abstract}

\section{Introduction}

The study of nonlinear optical (NLO) materials has gained increasing interest especially owing to their significance in laser technology and optoelectronics. Ultrafast electro-optical switches, optical signal processing and computing, data storage, and photonic technologies are just some of the various applications where these materials have become indispensable. ${ }^{1-8}$ One of the most sought-after nonlinear properties for these applications is the second harmonic generation (SHG), a phenomenon in which the material combines two photons into one, creating radiation with twice the frequency of the original. The fundamental requirement for a material to have SHG activity is to possess non-zero second-order nonlinear susceptibility $\chi^{(2)}$, which necessitates the compound to have non-zero first-order hyperpolarizability $\beta$ at the molecular level. ${ }^{9}$ It is highly beneficial if the

\footnotetext{
${ }^{a}$ Department of Chemistry, University of Jyväskylä, P. O. Box 35, FI-40014 Jyväskylä, Finland. E-mail: jari.a.konu@jyu.fi; Tel: +358-40-805-4406

${ }^{b}$ Nanoscience Center, University of Jyväskylä, P. O. Box 35, FI-40014 Jyväskylä, Finland

$\dagger$ Electronic supplementary information (ESI) available: A pdf file containing tables of crystallographic data (Tables S1-S3) and pertinent bond parameters (Tables S4-S16, together with molecular figures for atomic numbering scheme) as well as ${ }^{1} \mathrm{H}$ NMR (Fig. S1-S11) and IR spectra (Fig. S12-S22) for all compounds. This material is available free of charge. CCDC 2058507-2058519 for compounds

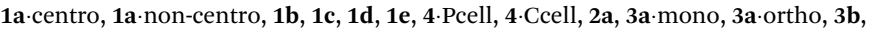
and 3c. For ESI and crystallographic data in CIF or other electronic format see DOI: 10.1039/d1nj00456e
}

NLO active material crystallizes in a non-centrosymmetric space group (lack of inversion symmetry) to avoid the effective cancelation of hyperpolarizability, even though centrosymmetric crystals have also been reported to display SHG through processes involving intermolecular interactions. ${ }^{10,11}$

Although most of the commercially available NLO crystals are based on inorganic compounds such as $\beta$-barium borate (BBO) and potassium titanyl phosphate (KTP), primarily owing to their high chemical and physical stability, ${ }^{12-14}$ the academic research on new NLO active materials has largely focused on organic "push-pull" molecules for which high SHG activities have been observed frequently. ${ }^{15-18}$ A group of compounds consistently showing remarkable SHG efficiencies are diarylethenes, commonly known as stilbenes (compound 1, Scheme 1). They have been studied extensively by both theoretical and experimental methods, ${ }^{19,20}$ and, for example, 3-methyl-4-methoxy-4'-nitrostilbene (MMONS, Scheme 1), the most efficient second order NLO material reported to date with the SHG efficiency of up to 1250 times of urea, ${ }^{21}$ belongs to this group of conjugated systems. Additionally, a variety of heteroaromatic, diarylethene-based systems where one or both aryl moieties have been replaced with thiophene, thiazole, or pyrrole rings have also been investigated. ${ }^{22-25}$ The primary aim of these studies was to increase the hyperpolarizability $(\beta)$ of the chromophores by altering the charge-transfer properties. While the electric field induced second harmonic generation (EFISHG) measurements of especially thiophene containing diarylethenes in solution have shown to improve the NLO properties at molecular 
<smiles>[R]c1cc(C=O)c([R])c([R])c1[R]</smiles>

1a: $\mathrm{R}_{1}=\mathrm{H}, \mathrm{R}_{2}=\mathrm{OCH}_{3}, \mathrm{R}_{3}=\mathrm{OCH}_{3}, \mathrm{R}_{4}=\mathrm{Cl}$ 1b: $\mathrm{R}_{1}=\mathrm{Br}, \mathrm{R}_{2}=\mathrm{H}, \mathrm{R}_{3}=\mathrm{NO}_{2}, \mathrm{R}_{4}=\mathrm{OH}$ 1c: $R_{1}=H, R_{2}=O_{3} H_{3}, R_{3}=H, R_{4}=H$

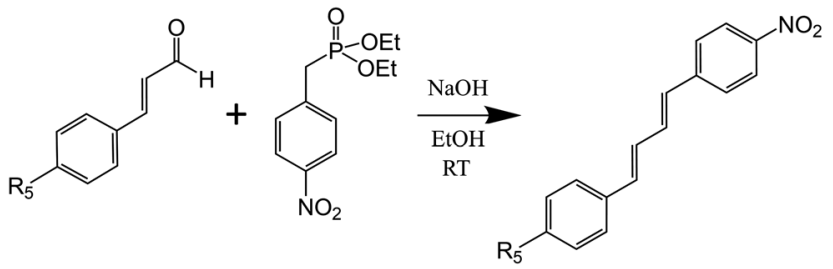

2a: $R_{5}=F \quad$ 2b: $R_{5}=\mathrm{OCH}_{3} \quad$ 2c: $\mathrm{R}_{5}=\mathrm{N}\left(\mathrm{CH}_{3}\right)_{2}$

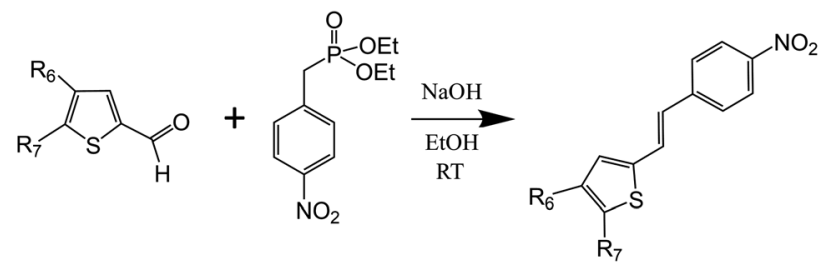

3a: $\mathrm{R}_{6}=\mathrm{Br}, \mathrm{R}_{7}=\mathrm{H} \quad 3 \mathrm{~b}: \mathrm{R}_{6}=\mathrm{H}, \mathrm{R}_{7}=\mathrm{CH}_{3} \quad$ 3c: $\mathrm{R}_{6}=\mathrm{H}, \mathrm{R}_{7}=\mathrm{SCH}_{3}$

Scheme 1 Synthesis of the stilbene (1), diphenylbutadiene (2), and phenylethenylthiophene (3) derivatives.

level, ${ }^{22-25}$ the information on SHG activity of these systems in the solid-state, requiring the most advantageous non-centrosymmetric molecular packing in the crystal lattice, is much more scarce.

We recently reported a novel method for producing NLO active lenses by stereolithographic (SLA) 3D printing technique. ${ }^{26}$ This new approach avoids the often tedious and time-consuming process of growing large single crystals by utilizing microcrystalline powders of NLO active components similarly to the Kurtz-Perry powder method for determination of relative SHG intensities. ${ }^{27}$ At the same time, the protective layer of photopolymer resin used in the SLA 3D printing could enable the use of labile organic chromophores as NLO active units. ${ }^{26}$ In this context and with the above considerations in mind, we have now investigated the conjugated, $-\mathrm{NO}_{2}$ substituted stilbene-based systems with the goal of producing new NLO active materials in the solid-state by the means of (1) changing the functional groups at the electron-donating end of stilbene, (2) extending the chain length between the aromatic groups to afford diarylbutadiene derivatives, and (3) changing one of the phenyl groups to thiophene. Consequently, we report here the synthesis, spectroscopic $\left({ }^{1} \mathrm{H}\right.$ NMR, IR, UV-Visible and fluorescence) and structural characterization (single-crystal XRD), and the SHG properties (Kurtz-Perry powder method) ${ }^{27}$ of stilbene (1a-e), diphenylbutadiene (2a-c), and phenylethenylthiophene (3a-c) derivatives (Scheme 1).

\section{Experimental methods}

\section{Reagents and general procedures}

The reactions were carried out in air. All the starting materials and solvents were purchased from commercial sources. Solvents were dried over $3 \AA$ molecular sieves and the remaining reagents were used without further purification: diethyl(4-nitrobenzyl)phosphonate (TCI Chemicals, >97.0\%), 4-methoxy-3-methylbenzaldehyde (Sigma-Aldrich, 99\%), 2-chloro-3,4-dimethoxybenzaldehyde (TCI Chemicals, >98.0\%), 5-bromo-3-nitrosalicylaldehyde (TCI Chemicals, $>97.0 \%$ ), 4-bromothiophene-2-carboxaldehyde (TCI Chemicals, $>98.0 \%$ ), 5-methylthiophene-2-carboxaldehyde (TCI Chemicals, >97.0\%), 4-fluorocinnamaldehyde (TCI Chemicals, $>95.0 \%$ ), sodium hydroxide (VWR Chemicals, 99\%), 4-anisaldehyde (Merck, 99\%), 3,4-dimethoxybenzaldehyde (Aldrich, 99\%), 5-(methylthio)thiophenecarboxaldehyde (TCI Chemicals, $>98.0 \%$ ), 4-methoxycinnamaldehyde (Sigma-Aldrich, $\geq 98 \%$ ), 4-dimethylaminocinnamaldehyde (TCI Chemicals, >98.0\%), $\mathrm{CH}_{2} \mathrm{Cl}_{2}$ (VWR Chemicals, 99\%), chloroform (Fisher Chemical, analytical reagent grade), acetone (Mallinckrodt, >99.5\%), Ethanol (Altia, >99.5\%). Elemental analyses were performed by analytical services at the Department of Chemistry, University of Jyväskylä.

\section{Spectroscopic methods}

The ${ }^{1} \mathrm{H}$ NMR spectra were obtained in $\mathrm{CD}_{2} \mathrm{Cl}_{2}$ at $30{ }^{\circ} \mathrm{C}$ on Bruker Avance III 300 spectrometer operating at $300.15 \mathrm{MHz}$. ${ }^{1} \mathrm{H}$ NMR spectra are referenced to the solvent signal and the chemical shifts are reported relative to $\left(\mathrm{CH}_{3}\right)_{4} \mathrm{Si}$. The IR spectra were measured with Bruker Alpha FTIR spectrometer. The extinction coefficients (molar absorptivity) were determined with PerkinElmer Lambda 650 spectrophotometer by measuring the absorbances of $1 \mathrm{mM}$ and $10 \mu \mathrm{M}$ solutions in $\mathrm{CH}_{2} \mathrm{Cl}_{2}$ (800 to $250 \mathrm{~nm})$. The fluorescence spectra of the compounds were recorded on a Varian Cary Eclipse spectrophotometer from 0.1-10 $\mu \mathrm{M}$ solutions in $\mathrm{CH}_{2} \mathrm{Cl}_{2}$.

\section{Nonlinear optical (NLO) measurements}

The nonlinear optical properties of compounds $1 \mathbf{1 a}-\mathbf{e}, \mathbf{2 a - c}$, and 3a-c were measured with Kurtz-Perry powder method ${ }^{27}$ by using femtosecond laser radiation at $1030 \mathrm{~nm}$. In addition, the second harmonic generation (SHG) was double-checked by using spectrally resolving detection scheme using Kurtz-Perry sample geometry. For these experiments, both femtosecond and nanosecond laser pulses were used. Femtosecond experiments were performed with the setup consisting an amplified femtosecond laser source at $1030 \mathrm{~nm}$ (Pharos, Light Conversion Ltd) running at $600 \mathrm{kHz}$ repetition rate. Generated SHG signal was detected by using a high-resolution spectrometer equipped with $300 \mathrm{~mm}$ spectrograph (Acton SpectraPro 300i) with spectroscopy CCD detector (Newton DU971N-BV, Andor). Nano-second laser pulses at $100 \mathrm{~Hz}$ repetition rate and at $1030 \mathrm{~nm}$ and $1060 \mathrm{~nm}$ were taken from the ns-OPO (Ekspla Ltd.). Spectrum of the SHG signal was recorded by using time-gated ICCD detector (ISTAR, Andor) with $150 \mathrm{~mm}$ spectrograph. (Acton SpectraPro 150i). The crystalline samples, apart from $\mathbf{1 b}$, were sieved to a particle size of $<125 \mu \mathrm{m}$ and placed into capillary 
tubes for the determination of relative SHG intensity of the compounds. A capillary tube with urea sieved to the same particle size was used as a reference.

X-Ray crystallography. Crystallographic data for compounds 1a·centro, 1a·non-centro, 1b, 1c, 1d, 1e, 4.Pcell, 4·Ccell, 2a, 3a. mono, $\mathbf{3 a} \cdot$ ortho, $\mathbf{3 b}$, and $\mathbf{3 c}$ are summarized in Tables S1-S3 (cf. ESI, $\dagger$ also for molecular figures with atomic numbering schemes and the tables of pertinent bond parameters). Crystals were coated with Fomblin ${ }^{\mathbb{R}} \mathrm{Y}$ oil and mounted on a MiTeGen loop. Diffraction data were collected on Rikagu-Oxford SuperNova Single or Dual Source diffractometers equipped with Atlas CCD area-detector using graphite monochromatized $\mathrm{CuK} \alpha$ radiation ( $\lambda=1.54184 \AA$; $1 \mathbf{1 a} \cdot$ centro, 1a·non-centro, 1b, 1c, 1e, 4.Pcell, $4 \cdot$ Ccell, $2 a$, and $3 \mathbf{b})$ or MoK $\alpha$ radiation $(\lambda=0.71073 \AA$; 1d, 3a-mono, 3a·ortho, and 3c) at -120 or $-150{ }^{\circ} \mathrm{C}$. The data were processed primarily by performing analytical numeric absorption correction using a multifaceted crystal with CrysAlisPro program. $^{28}$ All structures were solved by direct methods with SHELXS or SHELXT and refined by using SHELXL implemented in the Olex ${ }^{2}$ program package. ${ }^{29,30}$ After full-matrix least-squares refinement of the non-hydrogen atoms with anisotropic thermal parameters, the hydrogen atoms were placed in calculated positions $\left(\mathrm{C}-\mathrm{H}=0.93 \AA\right.$ for $-\mathrm{CH}$ and $0.98 \AA$ for $-\mathrm{CH}_{3}$ hydrogen atoms, and $\mathrm{O}-\mathrm{H}=0.82 \AA$ for $-\mathrm{OH}$ hydrogen atoms). The isotropic thermal parameters of the calculated hydrogen atoms were fixed at 1.2 $(-\mathrm{CH})$ or $1.5\left(-\mathrm{CH}_{3}\right)$ times that of the corresponding carbon or oxygen. In the final refinement, the calculated hydrogen atoms were riding on their respective carbon or oxygen atoms.

Preparation of 2-chloro-3,4-dimethoxy-4'-nitrostilbene (1a). $0.202 \mathrm{~g}(1.00 \mathrm{mmol})$ of 2-chloro-3,4-dimethoxybenzaldehyde was dissolved in $10 \mathrm{~mL}$ of ethanol and $0.22 \mathrm{~mL}(1.00 \mathrm{mmol})$ of diethyl(4-nitrobenzyl)phosphonate was added to the solution at $23{ }^{\circ} \mathrm{C} .3 \mathrm{~mL}$ of $1.5 \mathrm{M}$ of sodium hydroxide solution in ethanol was then added and the reaction mixture was stirred overnight. The resulting precipitate was then filtered and washed with $5 \mathrm{~mL}$ of cold ethanol. The reaction afforded $0.255 \mathrm{~g}$ of yellow powder ( $80 \%$ yield).

Anal. calcd (\%): C, 60.10; H, 4.41; N, 4.38 found: C, 59.54; H, 4.19; N, 4.40\%. ${ }^{1} \mathrm{H}$ NMR $\left(\mathrm{CD}_{2} \mathrm{Cl}_{2}, 30{ }^{\circ} \mathrm{C}\right): \delta 8.21\left[\mathrm{~m}, 2 \mathrm{H},-\mathrm{C}_{6} \mathrm{H}_{4} \mathrm{NO}_{2}\right]$, $\delta 7.68\left[\mathrm{~m}, 2 \mathrm{H},-\mathrm{C}_{6} \mathrm{H}_{4} \mathrm{NO}_{2}\right], \delta 7.65\left[\mathrm{~d}, 1 \mathrm{H},-\mathrm{CH}=\mathrm{CH}-,{ }^{3} J\left({ }^{1} \mathrm{H},{ }^{1} \mathrm{H}\right)=\right.$ $16 \mathrm{~Hz}], \delta 7.49\left[\mathrm{~m}, 1 \mathrm{H},-\mathrm{C}_{6} H_{2}\right], \delta 7.05\left[\mathrm{~d}, 1 \mathrm{H},-\mathrm{CH}=\mathrm{CH}-,{ }^{3} J\left({ }^{1} \mathrm{H},{ }^{1} \mathrm{H}\right)=\right.$ $17 \mathrm{~Hz}], \delta 6.93\left[\mathrm{~m}, 1 \mathrm{H},-\mathrm{C}_{6} H_{2}\right], \delta 3.91\left[\mathrm{~s}, 3 \mathrm{H},-\mathrm{OCH}_{3}\right], \delta 3.85[\mathrm{~s}, 3 \mathrm{H}$, $\left.-\mathrm{OCH}_{3}\right]$. X-Ray quality crystals of the two polymorphs of compound 1a (1a-centro and 1a-non-centro) as well as two polymorphs of the subsequent dimerization products (4. Pcell and 4.Ccell, $c f$. main text) were obtained by slow evaporation of ethanol/chloroform and ethanol/dichloromethane solutions at $23{ }^{\circ} \mathrm{C}$.

Preparation of 5-bromo-2-hydroxy-3-nitro-4' ${ }^{\prime}$-nitrostilbene (1b). $0.247 \mathrm{~g}$ (1.00 mmol) of solid 5-bromo-3-nitrosalicylaldehyde was dissolved in $15 \mathrm{~mL}$ of ethanol at $23{ }^{\circ} \mathrm{C} .0 .22 \mathrm{~mL}$ (1.00 mmol) of diethyl(4-nitrobenzyl)phosphonate was added to the solution. The flask was gently heated until all aldehyde had dissolved. $3 \mathrm{~mL}$ of $1.5 \mathrm{M}$ solution of sodium hydroxide in ethanol was then added and the reaction mixture was stirred overnight. The resulting precipitate was then filtered and washed with $5 \mathrm{~mL}$ of cold ethanol, affording $0.200 \mathrm{~g}$ of red-brown product ( $55 \%$ yield).
The product was then extracted with $\mathrm{CH}_{2} \mathrm{Cl}_{2} / \mathrm{H}_{2} \mathrm{O}$-mixture followed by evaporation of the organic phase to give an orange powder of $0.023 \mathrm{~g}$ (6\% yield) as the spectroscopically pure product.

Anal. calcd (\%): C, 46.05; H, 2.48; N, 7.67 found: C, 44.98; H, 2.64; N, 7.86\%. ${ }^{1} \mathrm{H}$ NMR $\left(\mathrm{CD}_{3} \mathrm{CN}, 30{ }^{\circ} \mathrm{C}\right): \delta 11.10[\mathrm{~s}, 1 \mathrm{H},-\mathrm{OH}], \delta$ $8.24\left[\mathrm{~m}, 3 \mathrm{H},-\mathrm{C}_{6} \mathrm{H}_{4} \mathrm{NO}_{2}(2 \mathrm{H})\right.$ and $\left.-\mathrm{C}_{6} \mathrm{H}_{2}(1 \mathrm{H})\right], \delta 8.04[\mathrm{~m}, 1 \mathrm{H}$, $\left.-\mathrm{C}_{6} \mathrm{H}_{2}\right], \delta 7.72\left[\mathrm{~m}, 2 \mathrm{H},-\mathrm{C}_{6} \mathrm{H}_{4} \mathrm{NO}_{2}\right], \delta 7.58[\mathrm{~d}, 1 \mathrm{H},-\mathrm{CH}=\mathrm{CH}-$, $\left.{ }^{3} J\left({ }^{1} \mathrm{H},{ }^{1} \mathrm{H}\right)=16 \mathrm{~Hz}\right], \delta 7.32\left[\mathrm{~d}, 1 \mathrm{H},-\mathrm{CH}=\mathrm{CH}-,{ }^{3} J\left({ }^{1} \mathrm{H},{ }^{1} \mathrm{H}\right)=16 \mathrm{~Hz}\right]$. $\mathrm{X}$-Ray quality crystals of compound $\mathbf{1 b}$ were obtained by slow evaporation of ethanol/chloroform solution at $23{ }^{\circ} \mathrm{C}$.

Preparation of 4-methoxy-4' $\mathbf{~}^{\prime}$-nitrostilbene (1c). $0.133 \mathrm{~g}(1.00 \mathrm{mmol})$ of 4-anisaldehyde was dissolved in $10 \mathrm{~mL}$ of ethanol and $0.22 \mathrm{~mL}$ (1.00 mmol) of diethyl(4-nitrobenzyl)phosphonate was added at $23{ }^{\circ} \mathrm{C}$. $3 \mathrm{~mL}$ of $1.5 \mathrm{M}$ solution of sodium hydroxide in ethanol was then added and the reaction mixture was stirred overnight. The resulting precipitate was then filtered and washed with $5 \mathrm{~mL}$ of cold ethanol. The reaction afforded $0.170 \mathrm{~g}$ of yellow powder (66\% yield).

Anal. calcd (\%): C, 70.57; H, 5.13; N, 5.49 found: C, 69.83; H, 4.82; N, 5.52\%. ${ }^{1} \mathrm{H}$ NMR $\left(\mathrm{CD}_{2} \mathrm{Cl}_{2}, 30{ }^{\circ} \mathrm{C}\right): \delta 8.19[\mathrm{~m}, 2 \mathrm{H}$, $\left.-\mathrm{C}_{6} \mathrm{H}_{4} \mathrm{NO}_{2}\right], \delta 7.63\left[\mathrm{~m}, 2 \mathrm{H},-\mathrm{C}_{6} \mathrm{H}_{4} \mathrm{NO}_{2}\right], \delta 7.52[\mathrm{~m}, 2 \mathrm{H}$, $-\mathrm{C}_{6} \mathrm{H}_{4} \mathrm{OMe}$ ], $\delta 7.27\left[\mathrm{~d}, 1 \mathrm{H},-\mathrm{CH}=\mathrm{CH}-,{ }^{3} J\left({ }^{1} \mathrm{H},{ }^{1} \mathrm{H}\right)=16 \mathrm{~Hz}\right], \delta$ $7.05\left[\mathrm{~d}, 1 \mathrm{H},-\mathrm{CH}=\mathrm{CH}-,{ }^{3} J\left({ }^{1} \mathrm{H},{ }^{1} \mathrm{H}\right)=16 \mathrm{~Hz}\right], \delta 6.94[\mathrm{~m}, 2 \mathrm{H}$, $-\mathrm{C}_{6} \mathrm{H}_{4} \mathrm{OMe}$ ], $\delta 3.84\left[\mathrm{~s}, 3 \mathrm{H},-\mathrm{OCH}_{3}\right]$. X-Ray quality crystals of compound 1c were obtained by slow evaporation of methanol solution at $23{ }^{\circ} \mathrm{C}$.

Preparation of 3,4-dimethoxy-4'-nitrostilbene (1d). $0.165 \mathrm{~g}$ (1.00 mmol) of solid 3,4-dimethoxybenzaldehyde was dissolved in $10 \mathrm{~mL}$ of ethanol at $23{ }^{\circ} \mathrm{C} .0 .22 \mathrm{~mL}(1.00 \mathrm{mmol})$ of diethyl(4-nitrobenzyl)phosphonate was added to the solution. $3 \mathrm{~mL}$ of 1.5 M solution of sodium hydroxide in ethanol was then added and the reaction mixture was stirred overnight. The resulting precipitate was then filtered and washed with $5 \mathrm{~mL}$ of cold ethanol. The reaction afforded $0.219 \mathrm{~g}$ of yellow powder $(77 \%$ yield).

Anal. calcd (\%): C, 67.36; H, 5.30; N, 4.91 found: C, 66.46; H, 5.08; N, 4.81\%. ${ }^{1} \mathrm{H}$ NMR $\left(\mathrm{CD}_{2} \mathrm{Cl}_{2}, 30{ }^{\circ} \mathrm{C}\right): \delta 8.20[\mathrm{~m}, 2 \mathrm{H}$, $\left.-\mathrm{C}_{6} \mathrm{H}_{4} \mathrm{NO}_{2}\right], \delta 7.64\left[\mathrm{~m}, 2 \mathrm{H},-\mathrm{C}_{6} \mathrm{H}_{4} \mathrm{NO}_{2}\right], \delta \quad 7.26[\mathrm{~d}, 1 \mathrm{H}$, $\left.-\mathrm{CH}=\mathrm{CH}-,{ }^{3} J\left({ }^{1} \mathrm{H},{ }^{1} \mathrm{H}\right)=16 \mathrm{~Hz}\right], \delta 7.12\left[\mathrm{~m}, 2 \mathrm{H},-\mathrm{C}_{6} H_{3}\right], \delta 7.05$ $\left[\mathrm{d}, 1 \mathrm{H},-\mathrm{CH}=\mathrm{CH}-,{ }^{3} J\left({ }^{1} \mathrm{H},{ }^{1} \mathrm{H}\right)=16 \mathrm{~Hz}\right], \delta 6.90\left[\mathrm{~m}, 2 \mathrm{H},-\mathrm{C}_{6} H_{3} \mathrm{O}\right], \delta$ $3.91\left[\mathrm{~s}, 3 \mathrm{H},-\mathrm{OCH}_{3}\right] \delta 3.87\left[\mathrm{~s}, 3 \mathrm{H},-\mathrm{OCH}_{3}\right]$. X-Ray quality crystals of compound 1d were obtained by slow evaporation of methanol solution at $23{ }^{\circ} \mathrm{C}$.

Preparation of 4-dimethylamino-4'-nitrostilbene (1e). $0.148 \mathrm{~g}$ (1.00 mmol) of 4-dimethylaminobenzaldehyde was dissolved in $10 \mathrm{~mL}$ of ethanol at $23{ }^{\circ} \mathrm{C} .0 .22 \mathrm{~mL}(1.00 \mathrm{mmol})$ of diethyl(4-nitrobenzyl)phosphonate was added to the solution. $3 \mathrm{~mL}$ of 1.5 $\mathrm{M}$ solution of sodium hydroxide in ethanol was then added and the reaction mixture was stirred overnight. The resulting precipitate was then filtered and washed with $5 \mathrm{~mL}$ of cold ethanol. The reaction afforded $0.182 \mathrm{~g}$ of red powder ( $68 \%$ yield).

Anal. calcd (\%): C, 71.62; H, 6.01; N, 10.44 found: C, 70.25; $\mathrm{H}, 5.81 ; \mathrm{N}, 10.32 \% .{ }^{1} \mathrm{H} \mathrm{NMR}\left(\mathrm{CD}_{2} \mathrm{Cl}_{2}, 30{ }^{\circ} \mathrm{C}\right): \delta 8.17[\mathrm{~m}, 2 \mathrm{H}$, $\left.-\mathrm{C}_{6} \mathrm{H}_{4} \mathrm{NO}_{2}\right], \delta 7.59\left[\mathrm{~m}, 2 \mathrm{H},-\mathrm{C}_{6} \mathrm{H}_{4} \mathrm{NO}_{2}\right], \delta \quad 7.45[\mathrm{~m}, 2 \mathrm{H}$, $\left.-\mathrm{C}_{6} \mathrm{H}_{4} \mathrm{NMe}_{2}\right], \delta 7.24\left[\mathrm{~d}, 1 \mathrm{H},-\mathrm{CH}=\mathrm{CH}-,{ }^{3} J\left({ }^{1} \mathrm{H},{ }^{1} \mathrm{H}\right)=16 \mathrm{~Hz}\right]$, $\delta 6.96\left[\mathrm{~d}, 1 \mathrm{H},-\mathrm{CH}=\mathrm{CH}-,{ }^{3} J\left({ }^{1} \mathrm{H},{ }^{1} \mathrm{H}\right)=16 \mathrm{~Hz}\right], \delta 6.72[\mathrm{~m}, 2 \mathrm{H}$, 
$\left.-\mathrm{C}_{6} \mathrm{H}_{4} \mathrm{NMe}_{2}\right], \delta 3.01\left[\mathrm{~s}, 6 \mathrm{H},-\mathrm{N}\left(\mathrm{CH}_{3}\right)_{2}\right]$. X-Ray quality crystals of the compound 1e were obtained by slow evaporation of methanol solution at $23{ }^{\circ} \mathrm{C}$.

Preparation of $\mathbf{4}^{\prime}$-fluoro-4 $\mathbf{4}^{\prime \prime}$-nitro-1,4-diphenyl-1,3-butadiene (2a). $0.151 \mathrm{~g}$ ( $1.00 \mathrm{mmol})$ of solid 4 -fluorocinnamaldehyde was dissolved in $10 \mathrm{~mL}$ of ethanol at $23{ }^{\circ} \mathrm{C} .0 .22 \mathrm{~mL}(1.00 \mathrm{mmol})$ of diethyl(4-nitrobenzyl)phosphonate was added to the solution. $3 \mathrm{~mL}$ of $1.5 \mathrm{M}$ solution of sodium hydroxide in ethanol was then added and the reaction mixture was stirred overnight. The resulting precipitate was then filtered and washed with $5 \mathrm{~mL}$ of cold ethanol. The reaction afforded $0.093 \mathrm{~g}$ of yellow powder (35\% yield).

Anal. calcd (\%): C, 71.36; H, 4.49; N, 5.20 found: C, 70.05; H, 4.33; N, 5.18\%. ${ }^{1} \mathrm{H}$ NMR $\left(\mathrm{CD}_{2} \mathrm{Cl}_{2}, 30{ }^{\circ} \mathrm{C}\right): \delta 8.18[\mathrm{~m}, 2 \mathrm{H}$, $\left.-\mathrm{C}_{6} \mathrm{H}_{4} \mathrm{NO}_{2}\right], \delta 7.58\left[\mathrm{~m}, 2 \mathrm{H},-\mathrm{C}_{6} \mathrm{H}_{4} \mathrm{NO}_{2}\right], \delta 7.47[\mathrm{~m}, 2 \mathrm{H}$, $\left.-\mathrm{C}_{6} \mathrm{H}_{4} \mathrm{OMe}\right], \delta$ 7.18-6.71 [m, 6H, $\left.-\mathrm{C}_{6} \mathrm{H}_{4} \mathrm{OMe} \&-\mathrm{CH}=\mathrm{CH}-\right]$. $\mathrm{X}$-Ray quality crystals of compound $2 \mathrm{a}$ were obtained by slow evaporation of acetone/water solution at $23{ }^{\circ} \mathrm{C}$.

Preparation of $4^{\prime}$-methoxy-4" $\mathbf{4}^{\prime \prime}$-nitro-1,4-diphenyl-1,3-butadiene (2b). $0.162 \mathrm{~g}$ (1.00 mmol) of solid 4-methoxycinnamaldehyde was dissolved in $10 \mathrm{~mL}$ of ethanol at $23{ }^{\circ} \mathrm{C} .0 .22 \mathrm{~mL}(1.00 \mathrm{mmol})$ of diethyl(4-nitrobenzyl)phosphonate was added to the solution. $3 \mathrm{~mL}$ of $1.5 \mathrm{M}$ solution of sodium hydroxide in ethanol was then added and the reaction mixture was stirred overnight. The resulting precipitate was then filtered and washed with $5 \mathrm{~mL}$ of cold ethanol. The reaction afforded $0.175 \mathrm{~g}$ of orange powder (62\% yield).

Anal. calcd (\%): C, 72.58; H, 5.38; N, 4.98 found: C, 71.36; H, 5.27; N, 5.01\%. ${ }^{1} \mathrm{H}$ NMR $\left(\mathrm{CD}_{2} \mathrm{Cl}_{2}, 30{ }^{\circ} \mathrm{C}\right): \delta 8.17\left[\mathrm{~m}, 2 \mathrm{H},-\mathrm{C}_{6} \mathrm{H}_{4} \mathrm{NO}_{2}\right]$, $\delta 7.57\left[\mathrm{~m}, 2 \mathrm{H},-\mathrm{C}_{6} H_{4} \mathrm{NO}_{2}\right], \delta 7.43\left[\mathrm{~m}, 2 \mathrm{H},-\mathrm{C}_{6} \mathrm{H}_{4} \mathrm{OMe}\right], \delta 7.14[\mathrm{q}, 1 \mathrm{H}$, $-\mathrm{CH}=\mathrm{CH}-], \delta 6.90\left[\mathrm{~m}, 3 \mathrm{H},-\mathrm{C}_{6} \mathrm{H}_{4} \mathrm{OMe} \&-\mathrm{CH}=\mathrm{CH}-\right], \delta 6.78[\mathrm{~d}, 1 \mathrm{H}$, $\left.-\mathrm{CH}=\mathrm{CH}-,{ }^{3} J\left({ }^{1} \mathrm{H},{ }^{1} \mathrm{H}\right)=15 \mathrm{~Hz}\right], \delta \quad 6.69[\mathrm{~d}, 1 \mathrm{H},-\mathrm{CH}=\mathrm{CH}-$, $\left.{ }^{3} J\left({ }^{1} \mathrm{H},{ }^{1} \mathrm{H}\right)=16 \mathrm{~Hz}\right], \delta 3.82\left[\mathrm{~s}, 3 \mathrm{H},-\mathrm{OCH}_{3}\right]$. X-Ray quality crystals of compound $\mathbf{2 b}$ were obtained by slow evaporation of dichloromethane solution at $23{ }^{\circ} \mathrm{C}$ and the structure was confirmed to be analogous to that reported previously ${ }^{31}$ by unit cell measurement.

Preparation of $4^{\prime}$-dimethylamino-4" ${ }^{\prime \prime}$-nitro-1,4-diphenyl-1,3butadiene (2c). $0.175 \mathrm{~g}$ (1.00 mmol) of solid 4-dimethylaminocinnamaldehyde was dissolved in $15 \mathrm{~mL}$ of ethanol at $23{ }^{\circ} \mathrm{C} .0 .22 \mathrm{~mL}$ (1.00 mmol) of diethyl(4-nitrobenzyl)phosphonate was added to the solution. $3 \mathrm{~mL}$ of $1.5 \mathrm{M}$ solution of sodium hydroxide in ethanol was then added and the reaction mixture was stirred overnight. The resulting precipitate was then filtered and washed with $5 \mathrm{~mL}$ of cold ethanol. The reaction afforded $0.1451 \mathrm{~g}$ of copper-brown product ( $49 \%$ yield).

Anal. calcd (\%): C, 73.44; H, 6.16; N, 9.52 found: C, 72.83; H, 6.07; N, 9.47\%. ${ }^{1} \mathrm{H}$ NMR $\left(\mathrm{CD}_{2} \mathrm{Cl}_{2}, 30{ }^{\circ} \mathrm{C}\right): \delta 8.15\left[\mathrm{~m}, 2 \mathrm{H},-\mathrm{C}_{6} \mathrm{H}_{4} \mathrm{NO}_{2}\right]$, $\delta 7.54\left[\mathrm{~m}, 2 \mathrm{H},-\mathrm{C}_{6} \mathrm{H}_{4} \mathrm{NO}_{2}\right], \delta 7.36\left[\mathrm{~m}, 2 \mathrm{H},-\mathrm{C}_{6} H_{4} \mathrm{NMe}_{2}\right], \delta 7.14$ [q, $1 \mathrm{H},-\mathrm{CH}=\mathrm{CH}-], \delta 6.87-6.68\left[\mathrm{~m}, 4 \mathrm{H},-\mathrm{C}_{6} \mathrm{H}_{4} \mathrm{NMe}_{2} \&-\mathrm{CH}=\mathrm{CH}-\right], \delta$ $6.62\left[\mathrm{~d}, 1 \mathrm{H},-\mathrm{CH}=\mathrm{CH}-,{ }^{3} J\left({ }^{1} \mathrm{H},{ }^{1} \mathrm{H}\right)=16 \mathrm{~Hz}\right], \delta 2.99[\mathrm{~s}, 6 \mathrm{H}$, $-\mathrm{N}\left(\mathrm{CH}_{3}\right)_{2}$ ]. X-Ray quality crystals of compound $2 \mathrm{c}$ were obtained by slow evaporation of dichloromethane solution at $23{ }^{\circ} \mathrm{C}$ and the structure was confirmed to be analogous to that reported previously $^{32}$ by unit cell measurement.

Preparation of 2-[(4-nitrophenyl)ethenyl]-4-bromothiophene (3a). $0.191 \mathrm{~g}$ (1.00 mmol) of solid 4-bromothiophene-2-carboxaldehyde was dissolved in $10 \mathrm{~mL}$ of ethanol at $23{ }^{\circ} \mathrm{C} .0 .22 \mathrm{~mL}(1.00 \mathrm{mmol})$ of diethyl(4-nitrobenzyl)phosphonate was added to the solution. $3 \mathrm{~mL}$ of $1.5 \mathrm{M}$ solution of sodium hydroxide in ethanol was then added and the reaction mixture was stirred overnight. The resulting precipitate was then filtered and washed with $5 \mathrm{~mL}$ of cold ethanol. The reaction afforded $0.186 \mathrm{~g}$ of yellow powder ( $60 \%$ yield).

Anal. calcd (\%): C, 46.47; H, 2.60; N, 4.52 found: C, 45.91; H, 2.62; N, 4.53\%. ${ }^{1} \mathrm{H}$ NMR $\left(\mathrm{CD}_{2} \mathrm{Cl}_{2}, 30{ }^{\circ} \mathrm{C}\right): \delta 8.20\left[\mathrm{~m}, 2 \mathrm{H},-\mathrm{C}_{6} \mathrm{H}_{4} \mathrm{NO}_{2}\right], \delta$ $7.62\left[\mathrm{~m}, 2 \mathrm{H},-\mathrm{C}_{6} \mathrm{H}_{4} \mathrm{NO}_{2}\right], \delta 7.34\left[\mathrm{~d}, 1 \mathrm{H},-\mathrm{CH}=\mathrm{CH}-,{ }^{3} J\left({ }^{1} \mathrm{H},{ }^{1} \mathrm{H}\right)=16\right.$ $\mathrm{Hz}], \delta 7.23\left[\mathrm{~m}, 1 \mathrm{H},-\mathrm{C}_{4} \mathrm{H}_{2} \mathrm{~S}\right], \delta 7.12\left[\mathrm{~m}, 1 \mathrm{H},-\mathrm{C}_{4} H_{2} \mathrm{~S}\right], \delta 7.01[\mathrm{~d}, 1 \mathrm{H}$, $\left.-\mathrm{CH}=\mathrm{CH}-,{ }^{3} \mathrm{~J}\left({ }^{1} \mathrm{H},{ }^{1} \mathrm{H}\right)=16 \mathrm{~Hz}\right]$. X-Ray quality crystals of compound 3a.mono were obtained by slow evaporation of ethanol/chloroform solution at $23{ }^{\circ} \mathrm{C}$, while the crystals of $3 \mathbf{a} \cdot$ ortho were obtained by slow evaporation of toluene solution at $23{ }^{\circ} \mathrm{C}$.

Preparation of 2-[(4-nitrophenyl)ethenyl]-5-methylthiophene (3b). $0.11 \mathrm{~mL}(1.00 \mathrm{mmol})$ of liquid 5-methylthiophene-2carboxaldehyde was dissolved in $10 \mathrm{~mL}$ of ethanol at $23{ }^{\circ} \mathrm{C}$. $0.22 \mathrm{~mL}$ (1.00 mmol) of diethyl(4-nitrobenzyl)phosphonate was added to the solution. $3 \mathrm{~mL}$ of $1.5 \mathrm{M}$ solution of sodium hydroxide in ethanol was then added and the reaction mixture was stirred overnight. The resulting precipitate was then filtered and washed with $5 \mathrm{~mL}$ of cold ethanol. The reaction afforded $0.191 \mathrm{~g}$ of yellow powder (78\% yield).

Anal. calcd (\%): C, 63.65; H, 4.52; N, 5.71 found: C, 62.70; H, 4.40; N, 5.59\%. ${ }^{1} \mathrm{H} \mathrm{NMR}\left(\mathrm{CD}_{2} \mathrm{Cl}_{2}, 30{ }^{\circ} \mathrm{C}\right): \delta 8.18\left[\mathrm{~m}, 2 \mathrm{H},-\mathrm{C}_{6} \mathrm{H}_{4} \mathrm{NO}_{2}\right]$, $\delta 7.58\left[\mathrm{~m}, 2 \mathrm{H},-\mathrm{C}_{6} \mathrm{H}_{4} \mathrm{NO}_{2}\right], \delta 7.35\left[\mathrm{~d}, 1 \mathrm{H},-\mathrm{CH}=\mathrm{CH}-,{ }^{3} J\left({ }^{1} \mathrm{H},{ }^{1} \mathrm{H}\right)=\right.$ $16 \mathrm{~Hz}], \delta 6.99\left[\mathrm{~m}, 1 \mathrm{H},-\mathrm{C}_{4} \mathrm{H}_{2} \mathrm{~S}\right], \delta 6.84\left[\mathrm{~d}, 1 \mathrm{H},-\mathrm{CH}=\mathrm{CH}-,{ }^{3} J\left({ }^{1} \mathrm{H},{ }^{1} \mathrm{H}\right)=\right.$ $16 \mathrm{~Hz}], \delta 6.72\left[\mathrm{~m}, 1 \mathrm{H},-\mathrm{C}_{4} \mathrm{H}_{2} \mathrm{~S}\right], \delta 2.51\left[\mathrm{~s}, 3 \mathrm{H},-\mathrm{CH}_{3}\right]$. X-Ray quality crystals of compound $\mathbf{3 b}$ were obtained by slow evaporation of ethanol/chloroform solution at $23{ }^{\circ} \mathrm{C}$.

Preparation of 2-[(4-nitrophenyl)ethenyl]-5-(methylthio)thiophe (3c). $0.152 \mathrm{~g}$ (1.00 mmol) of liquid (5-methylthio)thiophene2-carboxaldehyde was dissolved in $10 \mathrm{~mL}$ of ethanol at $23{ }^{\circ} \mathrm{C}$. $0.22 \mathrm{~mL}(1.00 \mathrm{mmol})$ of diethyl(4-nitrobenzyl)phosphonate was added to the solution. $3 \mathrm{~mL}$ of $1.5 \mathrm{M}$ of sodium hydroxide in ethanol was then added and the reaction mixture was stirred overnight. The precipitate was then filtered and washed with $5 \mathrm{~mL}$ of cold ethanol. The reaction afforded $0.224 \mathrm{~g}$ of orange powder (81\% yield).

Anal. calcd (\%): C, 56.29; H, 4.00; N, 5.05 found: C, 55.53; H, 3.97; N, 5.05\%. ${ }^{1} \mathrm{H}$ NMR $\left(\mathrm{CD}_{2} \mathrm{Cl}_{2}, 30{ }^{\circ} \mathrm{C}\right): \delta 8.19[\mathrm{~m}, 2 \mathrm{H}$, $\left.-\mathrm{C}_{6} \mathrm{H}_{4} \mathrm{NO}_{2}\right], \delta 7.59\left[\mathrm{~m}, 2 \mathrm{H},-\mathrm{C}_{6} H_{4} \mathrm{NO}_{2}\right], \delta 7.33[\mathrm{~d}, 1 \mathrm{H},-\mathrm{CH}=\mathrm{CH}-$, $\left.{ }^{3} J\left({ }^{1} \mathrm{H},{ }^{1} \mathrm{H}\right)=16 \mathrm{~Hz}\right], \delta 7.04\left[\mathrm{~m}, 1 \mathrm{H},-\mathrm{C}_{4} H_{2} \mathrm{~S}\right], \delta 6.96\left[\mathrm{~m}, 1 \mathrm{H},-\mathrm{C}_{4} \mathrm{H}_{2} \mathrm{~S}\right]$, $\delta 6.87\left[\mathrm{~d}, 1 \mathrm{H},-\mathrm{CH}=\mathrm{CH}-,{ }^{3} J\left({ }^{1} \mathrm{H},{ }^{1} \mathrm{H}\right)=16 \mathrm{~Hz}\right], \delta 2.55\left[\mathrm{~s}, 3 \mathrm{H},-\mathrm{CH}_{3}\right]$. $\mathrm{X}$-Ray quality crystals of compound $3 \mathrm{c}$ were obtained by slow evaporation of dichloromethane solution at $23{ }^{\circ} \mathrm{C}$.

\section{Results and discussion}

\section{Synthesis and crystal structures of compounds 1-4}

Horner-Wadsworth-Emmons synthetic method ${ }^{33}$ was used to synthesize the compounds 1-3 (Scheme 1). Equimolar amounts of aromatic aldehyde and phosphonate were reacted in basic conditions to yield spectroscopically and analytically pure products in good yields ( $c f$. ESI $\dagger$ for the ${ }^{1} \mathrm{H}$ NMR and IR spectra). The reactions 
resulted in the precipitation of pure products with the exception of compound $\mathbf{1 b}$ which was extracted with a mixture of $\mathrm{CH}_{2} \mathrm{Cl}_{2}$ and $\mathrm{H}_{2} \mathrm{O}$ followed by evaporation of the organic phase. All the compounds 1-3 possess $-\mathrm{NO}_{2}$ group at the electron withdrawing end of the push-pull molecules. Various substituents at the electron donating end were selected with a view to have an effect on the charge-transfer properties and therefore the molecular hyperpolarizability as well as to increase the possibility for the ideal, noncentrosymmetric packing of the chromophores in the crystal lattice (Scheme 1).

\section{Single-crystal X-ray structures of stilbene derivatives}

Similarly to many reported stilbene derivatives, ${ }^{20,21,34,35}$ the 2 chloro-3,4-dimethoxy-4'-nitrostilbene compound 1a shows polymorphism by crystallization in both centrosymmetric $\left(P 2_{1} / c, \mathbf{1 a}\right.$. centro) and non-centrosymmetric $\left(P 2_{1}, \mathbf{1 a} \cdot\right.$ non-centro $)$ space groups (Fig. 1, $c f$. ESI $\dagger$ for molecular figures of all the structures with atomic numbering schemes and the tables of pertinent bond parameters). Analogously to 3-methyl-4-methoxy-4'-nitrostilbene (MMONS), ${ }^{34}$ the discrete molecules in the centrosymmetric form 1a-centro are nearly planar with $\mathrm{ca} .3 .8^{\circ}$ angle between the aryl rings. By contrast, more pronounced twisting is notable in the non-centrosymmetric polymorph 1a-non-centro as evidenced by the corresponding angle of $c a .19 .2^{\circ}$ in the molecule. The primary driving force of the crystal packing in both polymorphs of 1a seems to be $\pi-\pi$ interactions, and while in 1a-centro this leads to a herringbone-like linear arrangement of molecular chains (Fig. 1a), in 1a-non-centro half of the molecules are rotated by $\mathrm{ca} .90^{\circ}$ (Fig. 1b). Consequently, only 1a.non-centro displays intermolecular $\mathrm{Cl}$. . ONO interactions of $3.27 \AA$ whereas the remaining close contacts $($ e.g. $\mathrm{MeO} \cdots \mathrm{H}$, $\mathrm{NO}_{2} \cdots \mathrm{H}$ ) are virtually insignificant in both polymorphs.

Stilbene 1a was also noted to go through, presumably, a photodimerization process of the ethenyl linkage to afford tetraaryl cyclobutane compound 4 (Fig. 2). Analogous behaviour has

a)

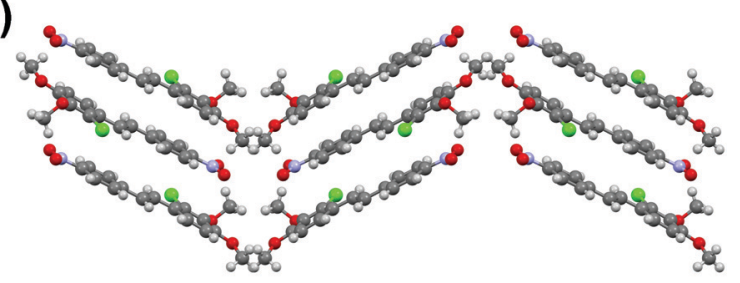

b)

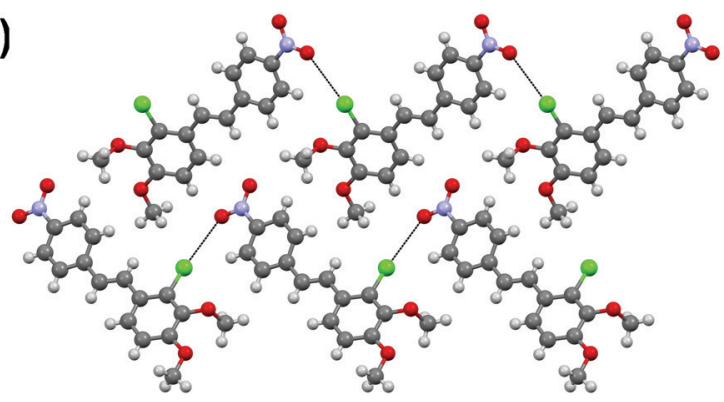

Fig. 1 Molecular packing in (a) 1a.centro (along c-axis) and (b) 1a.noncentro (along a-axis). been previously observed with other stilbenes and diaromatic olefins where a distance of $c a$. 3.5-4.2 A between the central $\mathrm{C}=\mathrm{C}$ bonds of adjacent molecules facilitates the solid state photodimerization process. ${ }^{36-38}$ Suitable alignment of molecules and a distance of $c a$. 3.7 $\AA$ between the double bonds can be found in 1a.centro whereas no such arrangement is observable in 1a.noncentro therefore suggesting that the former polymorph is the primary source for the formation of tetra-aryl cyclobutane dimer 4 .

The cyclobutane dimer $\mathbf{4}$ also shows polymorphism with crystallization in two monoclinic space groups, $P 2_{1} / n$ (4.Pcell) and $C 2 / c$ (4.Ccell). The difference in crystal packing can also be seen in a slightly different orientation of the phenyl groups around the central cyclobutane unit (Fig. 2). The dimerization results in the expected lengthening of the double bond in the ethenyl part of the original monomers from 1.333(2)-1.333(4) $\AA$ in 1a-non-centro and 1a·centro to $1.546(2)-1.558(2) \AA$ in $4 \cdot$ Pcell and 4 .Ccell. In addition, the $\mathrm{C}-\mathrm{C}$ bonds between the two stilbene units in cyclobutane rings in 4.Pcell and 4. Ccell are slightly longer than within each stilbene unit at 1.583(2)-

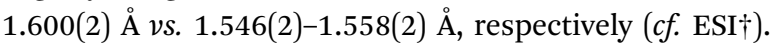

Stilbene derivative $\mathbf{1 b}$ with $-\mathrm{OH},-\mathrm{Br}$ and two $-\mathrm{NO}_{2}$ substituents crystallizes in a non-centrosymmetric space group $\mathrm{Cc}$. The phenyl rings within each molecule are strongly twisted compared to both polymorphs of 1a with an angle of $29.7^{\circ}$ between the aryl groups (Fig. 3a). Similarly to 1a, the crystal packing in $\mathbf{1 b}$ can be primarily contributed to $\pi-\pi$ interactions even though weak Br...ONO halogen contacts of $c a .3 .51$ and $3.37 \AA$, analogous to the $\mathrm{Cl}$. O ONO contacts in 1a.non-centro, also exist. The two orientations of independent molecules in $\mathbf{1 b}$ (Fig. 3b) and those observed in 1a.non-centro (Fig. 1b) also bear a close resemblance.

Stilbene 1c with $-\mathrm{NO}_{2}$ and $-\mathrm{MeO}$ substituents displays three independent molecules in the crystal lattice arranged in a rather random manner in triclinic space group $P \overline{1}$ (Fig. 4a). In contrast to the structures of $\mathbf{1 a}$ and $\mathbf{1 b}$, there is an apparent lack of $\pi-\pi$ interactions in 1c. Instead, one of the three independent molecules forms centrosymmetric dimers through weak $\mathrm{H}$ - . OMe hydrogen bonds between the $\mathrm{MeO}$ group and one of the hydrogens of the phenyl rings (Fig. 4b).

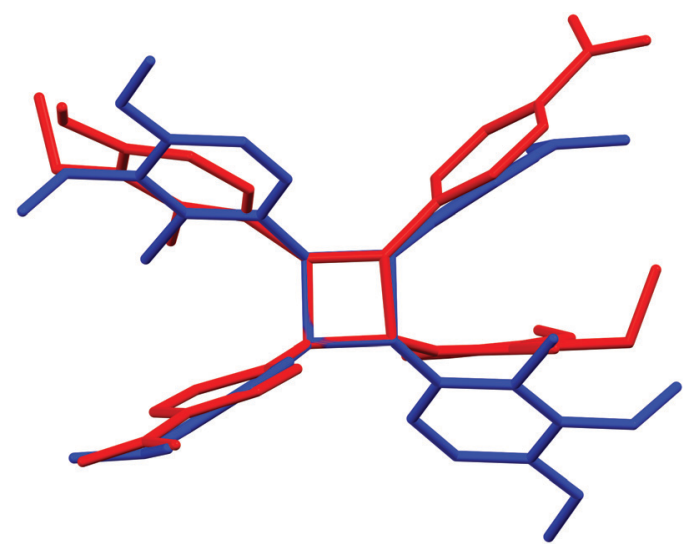

Fig. 2 The difference in phenyl ring and substituent orientations between P-cell (red) and C-cell (blue) tetra-aryl cyclobutanes 4. 
a)

b)
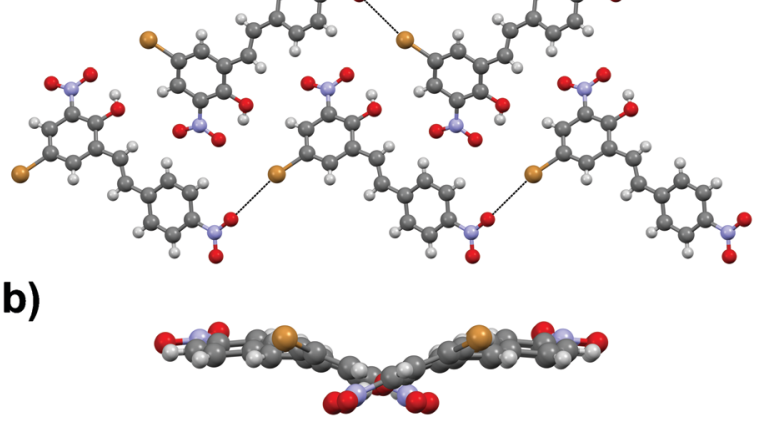

Fig. 3 (a) Crystal packing in compound $\mathbf{1 b}$ showing the orientation of the molecules within each layer (along a-axis) and (b) side view of the layer revealing the molecular distortion.

Stilbene derivative 1d with one $-\mathrm{NO}_{2}$ and two $-\mathrm{MeO}$ groups crystallizes in a centrosymmetric space group $P 2_{1} / c$. The aromatic rings within each molecule are heavily twisted with an angle of 43. $7^{\circ}$ between the rings (Fig. 5a). The molecules in $1 \mathrm{~d}$ form dimeric units through $\mathrm{MeO} \cdots \mathrm{H}_{3} \mathrm{CO}$ interactions (Fig. 5b) while the overall arrangement of molecules in the crystal lattice is rather arbitrary.

Stilbene congener $1 \mathrm{e}$ with $-\mathrm{NO}_{2}$ and $-\mathrm{NMe}_{2}$ substituents crystallizes in a non-centrosymmetric space group $P 2_{1}$. The structure shows disorder in which the molecules are organized in two orientations in the crystal lattice in 60:40 ratio ( $c f$. ESI $\dagger$ for a molecular figure of disorders in 1e). The slightly twisted stilbene molecules form planes along $a$-axis, and chains through weak $\mathrm{NO}_{2} \cdots\left(\mathrm{H}_{3} \mathrm{C}\right) \mathrm{N}$ hydrogen bonding along $c$-axis with alternating chain directions in the planes (Fig. 6).

\section{Single-crystal X-ray structures of diphenylbutadiene derivatives}

The diphenylbutadiene 2 a crystallizes in non-centrosymmetric space group Pc. Despite multiple crystallizations and several data collections, the crystal structure consistently shows orientational disorder where adjacent molecules are placed opposite

a)

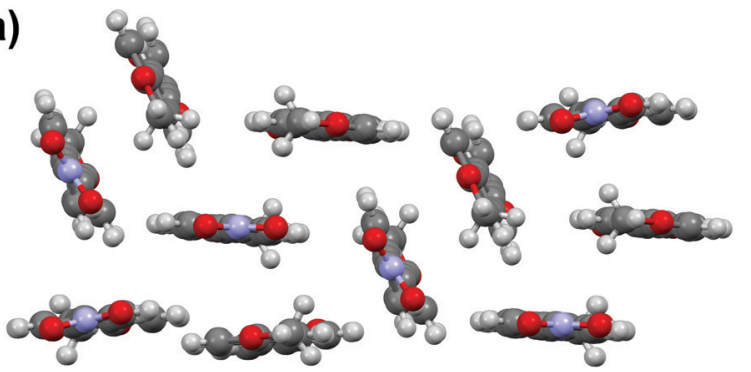

b)

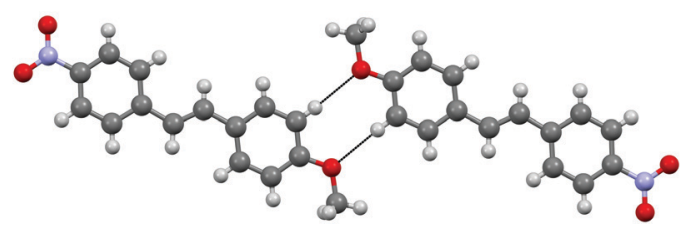

Fig. 4 (a) Orientation of stilbene molecules in the crystal lattice, and (b) close contacts in $\mathbf{1 c}$. a)

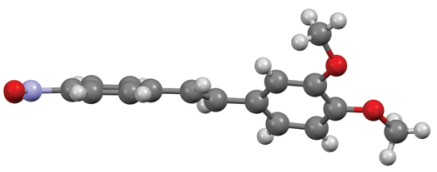

b)

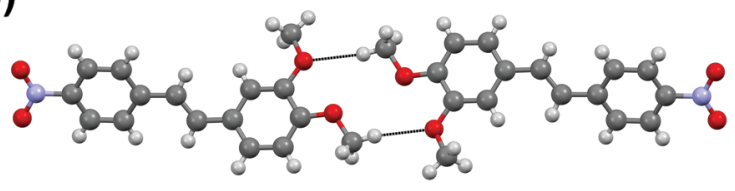

Fig. 5 (a) Rotation of the phenyl rings, and (b) the dimeric unit in $\mathbf{1 d}$.

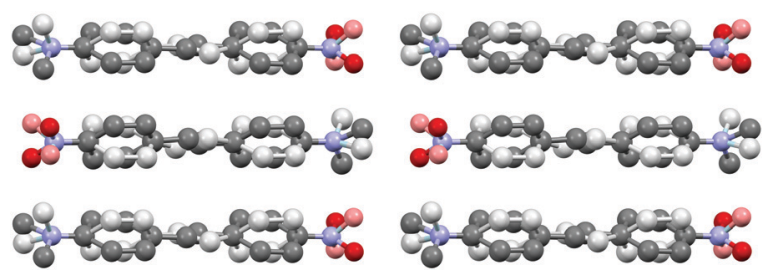

Fig. 6 Molecular packing of stilbene derivative 1e viewed along a-axis $(\mathrm{H}$ atoms removed for clarity, disorder indicated with lighter colours).

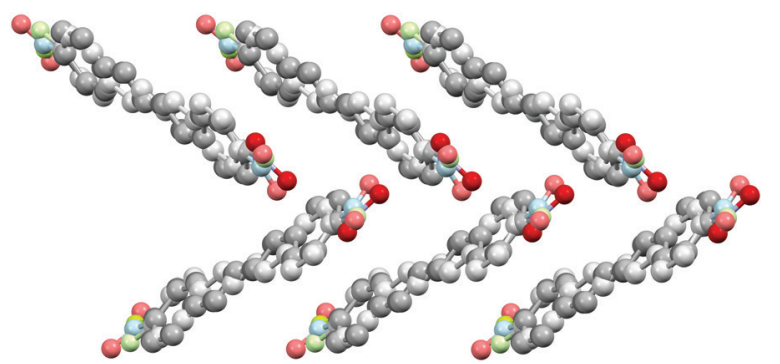

Fig. 7 Crystal structure of $\mathbf{2 a}$ with herringbone-style layers viewed along a-axis ( $\mathrm{H}$ atoms removed for clarity, disorder indicated with lighter colours).

directions in head-to-tail fashion ( $c f$. ESI $\dagger$ for a molecular figure of disorder in 2a). ${ }^{39}$ The slightly twisted diphenylbutadienes in 2a form planes along $a$-axis with alternating orientation of the molecules within each plane, and a herringbone style layering between the planes (Fig. 7). The crystal structures of diphenylbutadienes $\mathbf{2 b}$ and $2 \mathbf{c}$ have been reported previously (CSD entries YIQJEQ and EDUSAA). ${ }^{31,32}$ The former crystallizes in centrosymmetric space group $P \overline{1}$ with head-to-tail organization of the molecules. Despite the increase in chain length compared to stilbenes derivatives 1a-e, the conjugated molecules in 2b are notably planar (Fig. 8) forming a sheet-like structure with $\pi-\pi$ interactions leading to a relatively short distance of $3.70 \AA$ between centroids of the phenyl rings. The diphenylbutadiene 2c crystallizes in centrosymmetric space group $P 2_{1} / c$ and, analogously to $\mathbf{2 b}$, with markedly planar geometry within the molecules. In contrast to $\mathbf{2 b}$, however, there is some angling of the molecules between the layers (Fig. 8c), and therefore no $\pi-\pi$ interactions can be observed. Despite the extensive crystallization 
a)

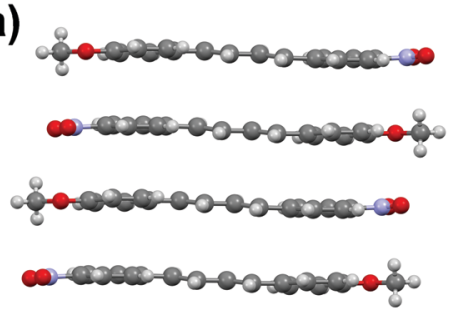

b)

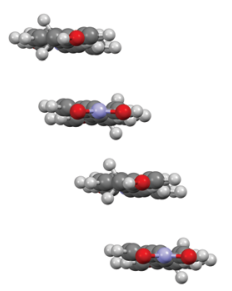

c)

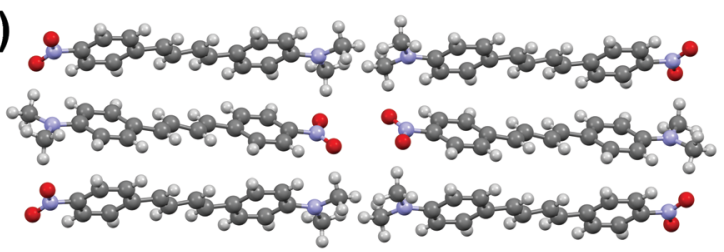

Fig. 8 (a) Side view and (b) end view of molecular arrangement in $\mathbf{2 b}$ (CSD entry "YIQJEQ"), ${ }^{31}$ and (c) molecular arrangement in 2c (CSD entry "EDUSAA"). ${ }^{32}$ Disorder in $\mathbf{2 c}$ has been removed for clarity.

efforts, no polymorphism and discovery of new, non-centrosymmetric crystal structures of $\mathbf{2 b}$ and $\mathbf{2 c}$ were observed.

\section{Single-crystal X-ray structures of phenylethenylthiophene derivatives}

Similarly to stilbene 1a, the phenylethenylthiophene 3a displays polymorphism by crystallizing in two centrosymmetric space groups, monoclinic $P 2_{1} / c$ (3a-mono) and orthorhombic $\mathrm{Pbca}$ (3a-ortho). Most notably, the phenyl and thiophene rings in 3a. mono are significantly twisted (by $12.4^{\circ}$ and $17.5^{\circ}$ in two independent molecules, respectively) while the analogous twisting in 3a.ortho is less pronounced $\left(4.7^{\circ}\right)$. Both polymorphs exhibit significant halogen bonding through $\mathrm{NO}_{2} \cdots \mathrm{Br}$ contacts of $c a .3 .06$ and $3.00 \AA$ in 3a.mono and 3a-ortho, respectively. Overall, the molecules form layered structure in 3a-mono (Fig. 9a) whereas in 3a.ortho the distortion between layers is notable (Fig. 9b).

Phenylethenylthiophene derivative $\mathbf{3 b}$ crystallizes in a centrosymmetric space group $P 2_{1} / n$ (Fig. 10a). The crystal structure displays two independent molecules in the unit cell with only slight deviation from planarity $\left(\mathrm{ca} .6 .8^{\circ}\right.$ and $5.7^{\circ}$ angles between the aromatic rings, respectively). One of the two molecules in asymmetric unit exhibits significant rotation of the $-\mathrm{NO}_{2}$ substituent with respect to the phenyl ring $\left(3.6^{\circ} \mathrm{vs} .27 .8^{\circ}\right.$ in the two distinct molecules). This behaviour is similar to $\mathbf{3 a} \cdot \mathbf{m o n o}$, in which the $-\mathrm{NO}_{2}$ groups show various degrees of rotation (3.2 $2^{\circ}$ and $13.7^{\circ}$ degrees), whereas in 3a-ortho all the substituents are virtually planar with respect to the phenyl and thiophene rings. The weak $\mathrm{NO}_{2} \cdots \mathrm{H}_{3} \mathrm{C}$ interactions result in chain formation with alternating directions and V-shaped geometry along the chains (Fig. 10b).

Phenylethenylthiophene $\mathbf{3 c}$ crystallizes in centrosymmetric space group $P 2_{1} / n$. The molecular chains form herringbonestyle planes with altering direction of the chains within each layer (Fig. 11). The only intermolecular interactions are the weak $\mathrm{NO}_{2} \cdots \mathrm{H}_{3} \mathrm{CS}$ contacts between the two substituents.
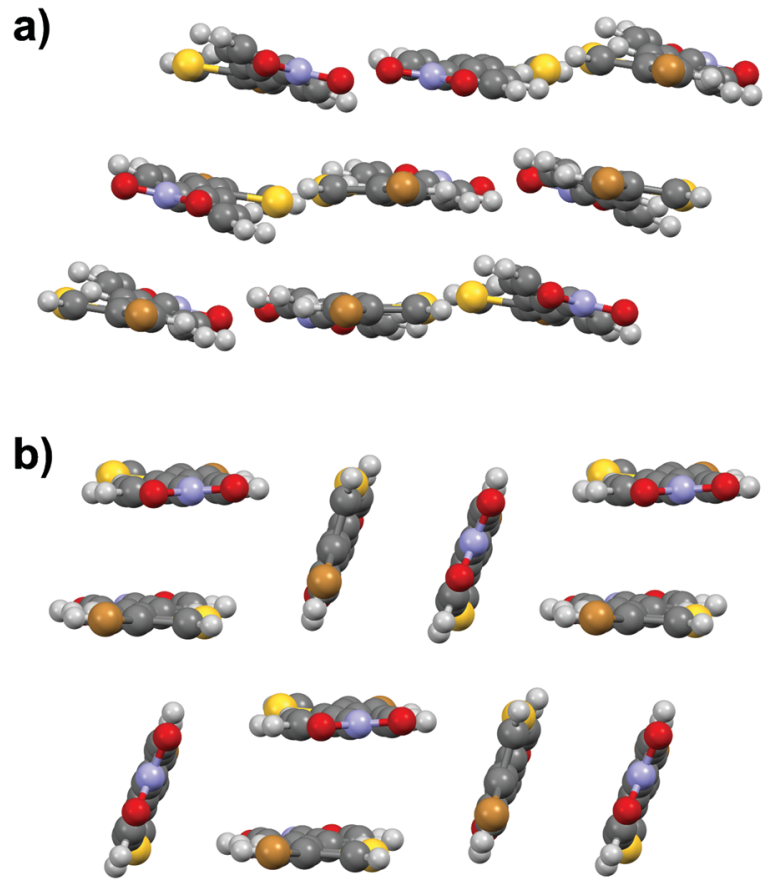

Fig. 9 (a) Crystal structure of 3a.mono viewed along b-axis, and (b) side view of $\mathbf{3 a} \cdot$ ortho.

\section{Nonlinear optical properties of compounds 1a-e, 2a-c and 3a-c}

The nonlinear optical properties of compounds $\mathbf{1 a - e , ~ 2 a - c , ~ a n d ~}$ 3a-c were initially measured with Kurtz-Perry powder method ${ }^{27}$ by using femtosecond laser radiation at $1030 \mathrm{~nm}$. In these experiments the SHG efficiency of MMONS (Scheme 1) displayed intensity of 61 times compared to that of urea (Table 1), far from the reported literatures values of $c a$. 750-1250 times urea. ${ }^{21}$ In view of the possible competing processes, such as two-photon fluorescence, the SHG intensities of MMONS, urea and the most promising new stilbene derivative, 1a-non-centro, were also measured by using nanosecond laser radiation at both 1030 and $1060 \mathrm{~nm}$ to closely reproduce the literature experiments (Table 1 and Fig. 12). ${ }^{21}$ While the switch from femtosecond to nanosecond laser source did increase the SHG intensity of MMONS from 61 to $\mathrm{ca}$. 200 times to that of urea, the change of the wavelength from 1030 to $1060 \mathrm{~nm}$ did not show significant effect on the SHG intensity consistently with the solid-state absorption maxima of MMONS reported at lower wavelength $(346 \text { and } 474 \mathrm{~nm})^{21}$ than either of the SHG signals at 515 and a)

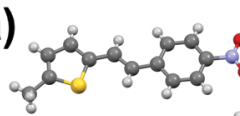

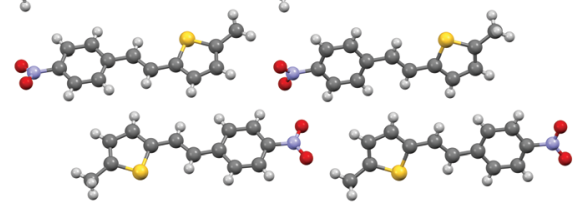

b)

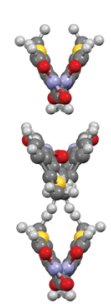

Fig. 10 (a) Crystal structure of compound $\mathbf{3 b}$ viewed along $b$-axis, and (b) side view of the layers showing the $\mathrm{V}$-shaped arrangement. 


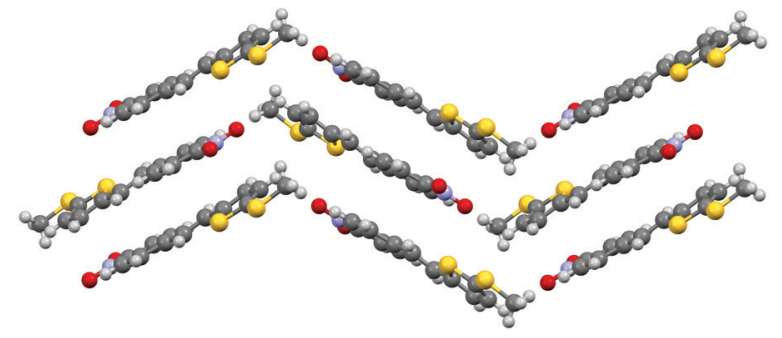

Fig. 11 Herringbone style layers of $3 c$ viewed along a-axis.

Table 1 Areas of SHG signals of $\mathbf{1 a} \cdot$ non-centro, $\mathbf{1 b}$ and $\mathbf{2 a}$ compared to urea and MMONS $^{a}$

Femtosecond laser radiation at $1030 \mathrm{~nm}$ (laser power: ${ }^{\mathrm{b}} 1.3 \mathrm{~mW},{ }^{\mathrm{c}} 6.2 \mathrm{~mW}$ )

\begin{tabular}{|c|c|c|c|c|c|}
\hline Sample $^{a}$ & $\begin{array}{l}\text { Signal } \\
\operatorname{area}^{b} \text { (a.u.) }\end{array}$ & $\begin{array}{l}\text { Relative area } \\
\text { (times urea) }\end{array}$ & Sample & $\begin{array}{l}\text { Signal } \\
\operatorname{area}^{c} \text { (a.u.) }\end{array}$ & $\begin{array}{l}\text { Relative area }{ }^{c} \\
\text { (times urea) }\end{array}$ \\
\hline Urea & 31000 & 1 & Urea & 397800 & 1 \\
\hline MMONS & 1890000 & 61.0 & $1 b$ & 15600 & 0.04 \\
\hline $\begin{array}{l}\text { 1a.non- } \\
\text { centro }\end{array}$ & 169700 & 5.5 & $2 a$ & 71300 & 0.18 \\
\hline
\end{tabular}

centro

Nanosecond laser radiation at ${ }^{\mathrm{d}} 1030$ and ${ }^{\mathrm{e}} 1060 \mathrm{~nm}$

Signal Relative area Signal Relative area Sample $^{a} \operatorname{area}^{\mathrm{d}}$ (a.u.) (times urea) ${ }^{\mathrm{d}}$ Sample $^{\mathrm{d}} \operatorname{area}^{\mathrm{e}}$ (a.u.) (times urea)

\begin{tabular}{|c|c|c|c|c|c|}
\hline Urea & 4760 & 1 & Urea & 7120 & 1 \\
\hline MMONS & 977100 & 205 & MMONS & 1498300 & 210 \\
\hline $\begin{array}{l}\mathbf{1 a} \cdot \text { non- } \\
\text { centro }\end{array}$ & 36640 & 7.7 & $\begin{array}{l}\text { 1a·non- } \\
\text { centro }\end{array}$ & 230650 & 32.4 \\
\hline
\end{tabular}

${ }^{a}$ Crystalline samples sieved to particle size of $<125 \mu \mathrm{m}$.

$530 \mathrm{~nm}$. However, the SHG intensity of MMONS still remained notably lower than the literature values (200 vs. 750-1250 times of urea) possibly owing to the fragmentation of fragile MMONS samples into too small microcrystalline material in the sieving process to reduce the SHG intensity, ${ }^{21}$ or because of partial contamination of the samples with inactive polymorphs of MMONS. $^{34}$ The latter, however, was rendered unlikely by space group determinations of several individual crystals and by X-ray powder measurements.

Hand-picked crystalline sample of the non-centrosymmetric polymorph 1a-non-centro displays SHG intensity of $c a$. 5.5 times to that of urea in the femtosecond laser experiments at $1030 \mathrm{~nm}$. The SHG intensity of 1a-non-centro increases to 7.7 and, significantly, 32.4 times to that of urea when nanosecond laser source is used at 1030 and $1060 \mathrm{~nm}$ wavelength, respectively. In all measurements the microcrystalline sample of 1a-non-centro shows detectable broad fluorescence indicating that some SHG efficiency is lost due to electronic excitation of the material, namely two-photon absorption of the laser radiation or absorption of the generated SH signal. The absorbance at $515 \mathrm{~nm}$ is virtually non-existing in $\mathrm{CH}_{2} \mathrm{Cl}_{2}$ solution (see below), but in the microcrystalline sample signal faces multiple interactions increasing absorption significantly. This may explain the observed difference in the intensity of SHG signal between two fundamental wavelengths. In addition, fluorescence is not
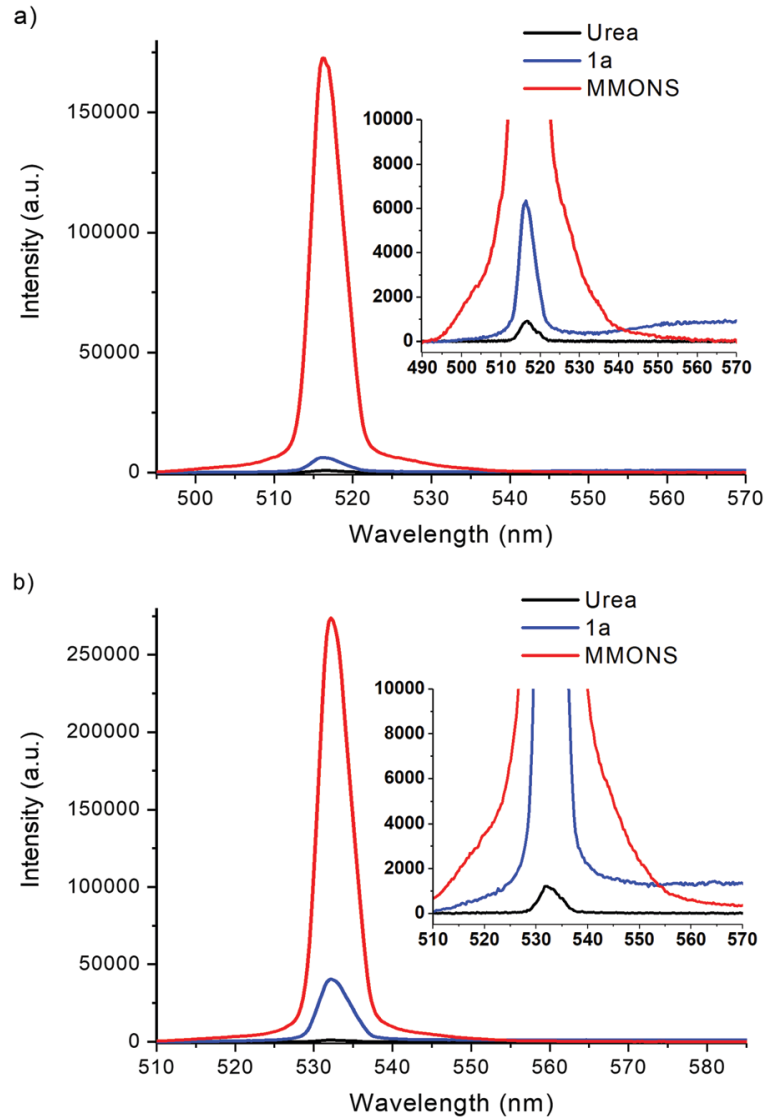

Fig. 12 SHG signals of 1a.non-centro, MMONS and urea generated at (a) $1030 \mathrm{~nm}$ and (b) $1060 \mathrm{~nm}$ with nanosecond laser source.

evident to be two-photon induced process as the intensity is not clearly dependent on the duration of laser pulse, suggesting that the generated SHG signal is to some extent absorbed in the sample.

The stilbene derivatives $\mathbf{1 b}$ and $\mathbf{1 e}$ also display non-centrosymmetric crystal packing in the solid state with the space groups $C c$ and $P 2_{1}$, respectively. However, only negligible SHG activity is observed for compound $\mathbf{1 b}$ ( 0.04 times that of urea), and virtually no SHG activity is detected for $1 \mathrm{e}$ with femtosecond laser experiments at $1030 \mathrm{~nm}$. The stilbene derivative $1 \mathrm{c}$ has also been reported to give rise to SHG signal, and polymorphism by crystallization in both centrosymmetric and non-centrosymmetric triclinic space groups. ${ }^{20,40,41}$ However, our investigation revealed only centrosymmetric space group $(P \overline{1})$ and no SHG activity for $1 c^{42}$

While the stilbene derivatives 1a-e expectedly display varying degree of SHG activity in the solid state depending on the efficiency of crystal packing, the alterations in the chain length between aryl groups to give diarylbutadienes $\mathbf{2}$ and changing one of the aryl groups to thiophene in compounds 3 resulted primarily in centrosymmetric arrangements of the chromophores despite the extensive crystallization efforts to obtain non-centrosymmetric polymorphs. Consequently, among all the derivatives of $\mathbf{2}$ and $\mathbf{3}$, only the diarylbutadiene compound 2a shows SHG intensity ( 0.18 times of urea) consistently with the non-centrosymmetric space group $P c$. 
It has been suggested that the highest recorded SHG activity of 3-methyl-4-methoxy-4'-nitrostilbene (MMONS) arises partly from the strong $\pi-\pi$ interactions that enhance the intermolecular charge-transfer and, consequently, the second order polarizability. ${ }^{21}$ In accordance, MMONS displays distances as short as ca. $3.56 \AA$ between the phenyl ring centroids despite the two distinct orientations of the molecules. The same distances in stilbene derivatives $\mathbf{1 a} \cdot$ non-centro and $\mathbf{1 b}$ are $c a$. 4.22 and $3.82 \AA$, respectively, even though it is the former chromophore that displays higher SHG intensity. This is likely a result of the better arrangement of polar centres in the crystal lattice of 1a-non-centro and the presence of electron withdrawing $-\mathrm{NO}_{2}$ group also in the "push" part of the chromophore $\mathbf{1 b}$. In contrast to the aforementioned compounds, the non-centrosymmetric stilbene derivative 1e does not show significant $\pi-\pi$ interactions, which is possibly contributing to the virtual absence of SHG activity.

\section{Optical spectroscopy of compounds 1-3}

The absorption spectra of compounds 1-3 were measured in $\mathrm{CH}_{2} \mathrm{Cl}_{2}$ at room temperature (Table 2 and Fig. 13). All compounds display one high and one low energy absorption maximum in solution, albeit the former is observable only as a small shoulder with the solvent signal in the case of stilbene derivatives 1a and 1c. Additionally, stilbene congener $\mathbf{1 b}$, the only compound with $-\mathrm{NO}_{2}$ group at both ends of the molecule, displays a distinct shoulder also at $410 \mathrm{~nm}$. The high energy (low wavelength) absorption maxima show relatively narrow range of 278-303 $\mathrm{nm}$ for stilbene derivatives 1, 289-322 $\mathrm{nm}$ for diphenylbutadiene compounds 2,

Table 2 Absorption and fluorescence spectroscopic properties of compounds 1-3

\begin{tabular}{llllll}
\hline \multicolumn{5}{l}{ Absorption bands } \\
\hline & $\lambda_{\mathrm{Abs}^{b}}{ }^{a}(\mathrm{~nm})$ & $\varepsilon^{c}\left(\mathrm{M}^{-1} \mathrm{~cm}^{-1}\right)$ & & $\lambda_{\mathrm{Abs}^{b}}{ }^{b}(\mathrm{~nm})$ & $\varepsilon^{c}\left(\mathrm{M}^{-1} \mathrm{~cm}^{-1}\right)$ \\
\hline 1a & 365 & 17200 & 2a & 381 & 23350 \\
& & & & 289 & 10700 \\
1b & 336 & 23800 & $2 b$ & 401 & 36450 \\
& 278 & 13700 & & 301 & 16350 \\
1c & 376 & 23100 & 2c & 452 & 35350 \\
& & & & 322 & 18450 \\
1d & 385 & 24350 & 3a & 358 & 10600 \\
& 280 & 13000 & & 272 & 13750 \\
1e & 439 & 23850 & $3 b$ & 390 & 16300 \\
& 303 & 12750 & & 278 & 10800 \\
& & & $3 c$ & 397 & 27350 \\
& & & & 291 & 8850 \\
\hline
\end{tabular}

Fluorescence bands $^{d}$

\begin{tabular}{llllll}
\hline \multicolumn{2}{c}{$\lambda_{\mathrm{Ex}}{ }^{e}(\mathrm{~nm})$} & $\lambda_{\mathrm{Em}}{ }^{f}(\mathrm{~nm})$ & $\Delta \nu^{g}\left(\mathrm{~cm}^{-1}\right)$ & \multicolumn{3}{c}{$\lambda_{\mathrm{Ex}}{ }^{e}(\mathrm{~nm})$} & $\lambda_{\mathrm{Em}}{ }^{f}(\mathrm{~nm})$ & $\Delta \nu^{g}\left(\mathrm{~cm}^{-1}\right)$ \\
\hline 1a 380 & 560 & 9540 & 2a 380 & 550 & 8065 \\
1c 380 & 585 & 9502 & 2b 400 & 615 & 8677 \\
1d 390 & 605 & 9445 & 2c 460 & 780 & 9303 \\
1e 450 & 730 & 9080 & 3a 380 & 520 & 8702 \\
& & & 3b 395 & 570 & 8097 \\
& & & 3c 400 & 635 & 9441
\end{tabular}

${ }^{a} 1 \mathrm{mM}$ and $10 \mu \mathrm{M}$ sol. in $\mathrm{CH}_{2} \mathrm{Cl}_{2}$ at $23{ }^{\circ} \mathrm{C} .{ }^{b}$ Absorption maximum. ${ }^{c}$ Extinction coefficient. ${ }^{d} 0.1-10 \mu \mathrm{M}$ solutions in $\mathrm{CH}_{2} \mathrm{Cl}_{2}$ at $23{ }^{\circ} \mathrm{C}$.

${ }^{e}$ Excitation maximum. ${ }^{f}$ Emission maximum. ${ }^{g}$ Stokes shift in wavenumbers calculated by the equation $\left(10^{7} / \lambda_{\mathrm{Abs}}\right)-\left(10^{7} / \lambda_{\mathrm{Em}}\right)$. a)
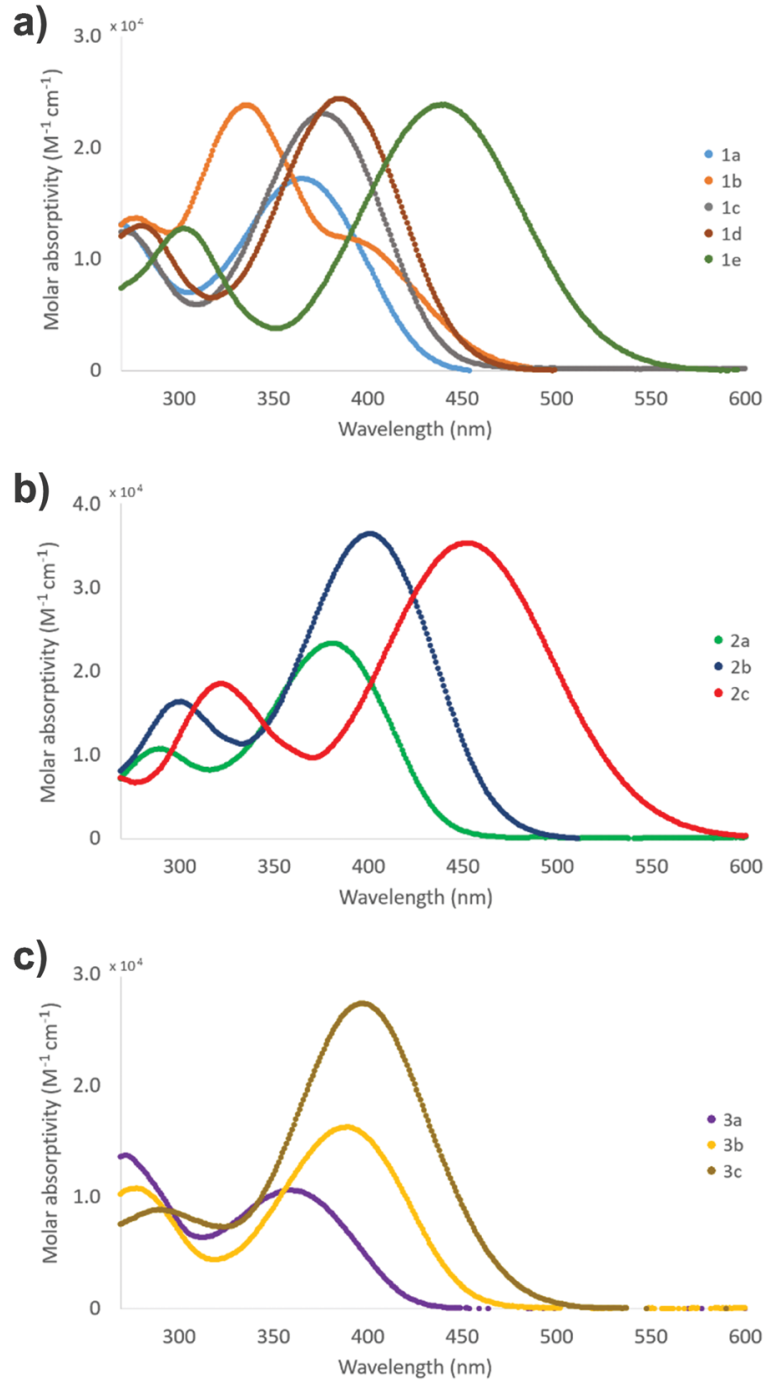

Fig. 13 Visible spectra of compounds (a) $1 \mathrm{a}-\mathbf{e}$, (b) $2 \mathrm{a}-\mathrm{c}$ and (c) $3 \mathrm{a}-\mathrm{c}(1 \mathrm{mM}$ and $10 \mu \mathrm{M}$ sol. in $\mathrm{CH}_{2} \mathrm{Cl}_{2}$ at $23^{\circ} \mathrm{C}$ ).

and 272-291 nm for phenylethenylthiophene species 3, while the corresponding low energy (high wavelength) bands exhibit significantly broader range of $336-439 \mathrm{~nm}$ for 1a-e, $381-452 \mathrm{~nm}$ for $\mathbf{2 a - c}$ and 358-397 nm for 3a-c. Expectedly, all the extinction coefficient values of $c a$. $9-37 \times 10^{3} \mathrm{M}^{-1} \mathrm{~cm}^{-1}$ are in the range typically observed for $\pi \rightarrow \pi^{*}$ transition. Given the wider wavelength range observed for the low energy absorption maxima, these bands are likely reflecting the modifications made by substituent alterations at the electron donating part of compounds 1-3 whereas the high energy bands in the absorption spectra are contributed to the electron withdrawing, $-\mathrm{NO}_{2}$ substituted end of the conjugated push-pull systems where no alterations were made within each series. Consistently, both diphenylbutadiene (2) and phenylethenylthiophene (3) derivatives exhibit a steady red shift in the low energy absorption maximum following the approximate order of increasing electron donating power of the substituents: $\mathrm{F}(2 \mathbf{a}, 381 \mathrm{~nm})<\mathrm{OCH}_{3}(2 \mathbf{b}, 401 \mathrm{~nm})<\mathrm{NMe}_{2}(2 \mathbf{c}, 452 \mathrm{~nm})$, and $\mathrm{Br}(3 \mathbf{a}, 358 \mathrm{~nm})<\mathrm{CH}_{3}(3 \mathbf{b}, 390 \mathrm{~nm})<\mathrm{SCH}_{3}(3 \mathbf{c}, 397 \mathrm{~nm})$, respectively. Similarly, stilbene derivative $1 \mathbf{e}$ with the strongest 

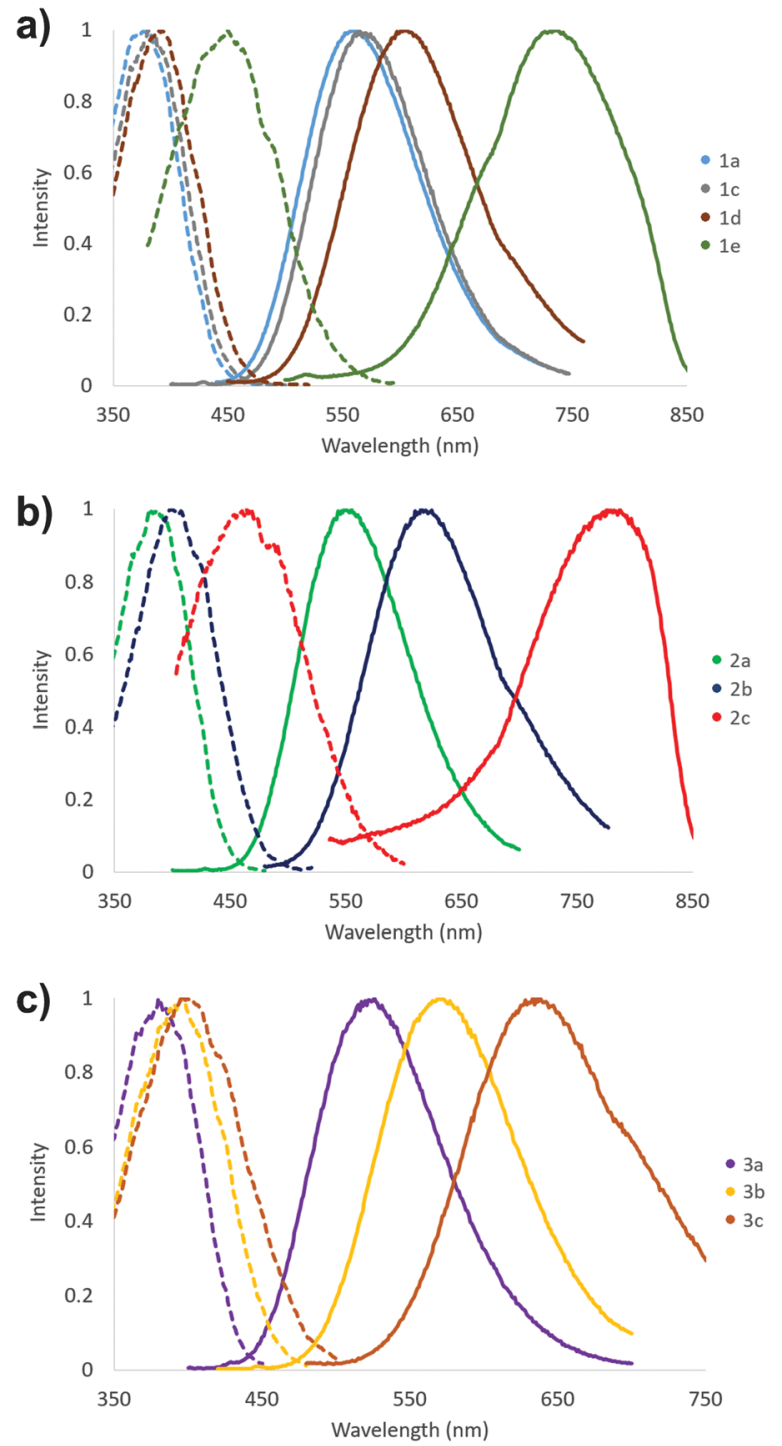

Fig. 14 Fluorescence spectra of compounds (a) 1a, $1 c-1 e$, (b) $2 a-c$ and (c) $3 a-c$ (emission spectra: solid line, excitation spectra: dotted line, 0.1-10 $\mu \mathrm{M}$ sol. in $\mathrm{CH}_{2} \mathrm{Cl}_{2}$ at $23^{\circ} \mathrm{C}$ ).

electron donating group $\left(\mathrm{NMe}_{2}\right)$ gives the lowest energy absorption maximum of the series at $439 \mathrm{~nm}$.

The fluorescent nature of stilbene and its derivatives is well established and various aspects of their optical, photophysical and photochemical properties have been exhaustively studied. ${ }^{43-47}$ Consistently with the high optical activity, the stilbene (1), diphenylbutadiene (2) and phenylethenylthiophene (3) derivatives in this investigation all show fluorescent properties with the exception of compound $1 \mathbf{b}$ (Table 2 and Fig. 14). In contrast to the two absorption bands, only single maximum with poorly resolved shoulders is observed in the excitation spectra of all the compounds 1-3 in $\mathrm{CH}_{2} \mathrm{Cl}_{2}$ at room temperature. However, the wavelength of the excitation maximum of each derivative displays close correlation with the corresponding low energy absorption band. Similarly to the absorption spectra, both the excitation and emission spectra of compounds 1-3 exhibit more pronounced red shift together with the increasing electron donating power of the substituent(s) within each series. Accordingly, the $-\mathrm{NMe}_{2}$ containing derivatives $1 \mathrm{e}$ and $\mathbf{2 c}$ give rise to the highest wavelength excitation and emission maxima. The large Stokes red shift values expectedly indicate high dipole moment in the excited state for all the compounds 1-3 in $\mathrm{CH}_{2} \mathrm{Cl}_{2}$ as has been previously demonstrated, for example, for compound $1 \mathrm{e}^{43}$

\section{Conclusions}

We report here the preparation and characterization of conjugated stilbene, diphenylbutadiene and phenylethenylthiophene based diaromatic compounds and their SHG activities measured from the crystalline samples by the Kurtz-Perry powder method. The most significant activity was observed for the stilbene 1a, which produces SHG signal with intensity $c a$. 32 times stronger than that of the urea reference when nanosecond laser radiation at $\mathbf{1 0 6 0} \mathrm{nm}$ is applied. The stilbene derivative $\mathbf{1 b}$ and diphenylbutadiene 2a also display SHG activity, albeit with significantly lower intensity compared to 1a. The often high SHG intensities reported for stilbene derivatives have been contributed, in part, to the strong $\pi-\pi$ interactions that enhance the intermolecular charge-transfer and, consequently, the second order polarizability. ${ }^{21}$ Consistently, the stilbene derivative 1a exhibits somewhat weaker $\pi-\pi$ interactions compared to 3-methyl-4-methoxy-4'-nitrostilbene (MMONS, Scheme 1) with significantly higher SHG intensity.

Our efforts to further investigate the effect of weak interactions to the NLO properties by changing the functional groups at the electron-donating end of stilbene, the extended chain length between the aromatic groups in diarylbutadienes and with thiophene derivatives were hampered by the extensive polymorphism that resulted in mainly centrosymmetric, NLO inactive chromophores despite the comprehensive crystallization efforts. Even the stilbene 1a with notable SHG activity also crystallizes in centrosymmetric, inactive space group and goes through, presumably, a photodimerization process to form two polymorphs of the tetraaryl cyclobutane 4. Nevertheless, the high SHG intensities of especially 3-methyl-4-methoxy-4'-nitrostilbene (MMONS) and congeneric derivative 1a make them attractive chromophores for future studies to produce NLO active lenses by stereolithographic 3D printing technique. ${ }^{26}$ Furthermore, the current study illustrates the versatility of the structural, chemical and optical properties in these diaromatic, conjugated systems as also evidenced by their fluorescent nature in solution.

\section{Conflicts of interest}

There are no conflicts to declare.

\section{Acknowledgements}

The authors gratefully acknowledge financial support from the Finnish Cultural Foundation and the Magnus Ehrnrooth Foundation. 


\section{References}

1 S. Tao, T. Miyagoe, A. Maeda, H. Matsuzaki, H. Ohtsu, M. Hasegawa, S. Takaishi, M. Yamashita and H. Okamoto, Adv. Mater., 2007, 19, 2707-2710.

2 J. M. Hales, S. Zheng, S. Barlow, S. R. Marder and J. W. Perry, J. Am. Chem. Soc., 2006, 128, 11362-11363.

3 B. Champagne, A. Plaquet, J.-L. Pozzo, V. Rodriguez and F. Castet, J. Am. Chem. Soc., 2012, 134, 8101-8103.

4 J. N. Zhang, X. Q. Wang, Q. Ren, H. L. Yang, J. W. Chen, Q. Sun, G. C. Li and T. B. Li, Opt. Laser Technol., 2011, 43, 679-682.

5 S. Di Bella, C. Dragonetti, M. Pizzotti, D. Roberto, F. Tessore and R. Ugo, in Molecular Organometallic Materials for Optics, Topics in Organometallic Chemistry, ed. H. Le Bozec and V. Guerchais, Coordination and Organometallic Complexes as Second-Order Nonlinear Optical Molecular Materials, Springer, Berlin, Heidelberg, ch. 1, vol. 28, 2010, pp. 1-55.

6 K. B. Manjunatha, R. Dileep, G. Umesh and B. R. Bhat, Opt. Laser Technol., 2013, 52, 103-108.

7 V. Nalla, R. Medishetty, Y. Wang, Z. Bai, H. Sun, J. Wei and J. J. Vittal, IUCrJ, 2015, 2, 317-321.

8 C.-F. Sun, C.-L. Hu, X. Xu, J.-B. Ling, T. Hu, F. Kong, X.-F. Long and J.-G. Mao, J. Am. Chem. Soc., 2009, 131, 9486-9487.

9 R. W. Boyd, Nonlinear Optics, Academic Press, 3rd edn, 2008.

10 G. J. Ashwell, G. Jefferies, D. G. Hamilton, D. E. Lynch, M. P. S. Roberts, G. S. Bahra and C. R. Brown, Nature, 1995, 375, 385-388.

11 G. J. Ashwell, Adv. Mater., 1996, 8, 248-250.

12 C. Chuantian, W. Bochang, J. Aidong and Y. Guiming, Sci. Sin., Ser. B, 1985, 28, 235-243.

13 F. C. Zumsteg, J. D. Bierlein and T. E. Gier, J. Appl. Phys., 1976, 47, 4980-4985.

14 J. D. Bierlein and H. Vanherzeele, J. Opt. Soc. Am. B, 1989, 6, 622.

15 I. Ledoux, C. Lepers, A. Périgaud, J. Badan and J. Zyss, Opt. Commun., 1990, 80, 149-154.

16 S. R. Marder, J. W. Perry and C. P. Yakymyshyn, Chem. Mater., 1994, 6, 1137-1147.

17 P. S. Patil, S. M. Dharmaprakash, H.-K. Fun and M. S. Karthikeyan, J. Cryst. Growth, 2006, 297, 111-116.

18 B. F. Levine, C. G. Bethea, C. D. Thurmond, R. T. Lynch and J. L. Bernstein, J. Appl. Phys., 1979, 50, 2523-2527.

19 L. T. Cheng, W. Tam, S. H. Stevenson, G. R. Meredith, G. Rikken and S. R. Marder, J. Phys. Chem., 1991, 95, 10631-10643.

20 Y. Wang, W. Tam, S. H. Stevenson, R. A. Clement and J. Calabrese, Chem. Phys. Lett., 1988, 148, 136-141.

21 W. Tam, B. Guerin, J. C. Calabrese and S. H. Stevenson, Chem. Phys. Lett., 1989, 154, 93-96.

22 P. R. Varanasi, A. K.-Y. Jen, J. Chandrasekhar, I. N. N. Namboothiri and A. Rathna, J. Am. Chem. Soc., 1996, 118, 12443-12448.

23 A. K.-Y. Jen, Y. Cai, P. V. Bedworth and S. R. Marder, Adv. Mater., 1997, 9, 132-135.

24 K. Mandal, T. Kar, P. K. Nandi and S. P. Bhattacharyya, Chem. Phys. Lett., 2003, 376, 116-124.

25 V. P. Rao, A. K.-Y. Jen, K. Y. Wong and K. J. Drost, Tetrahedron Lett., 1993, 34, 1747-1750.
26 E. Kukkonen, E. Lahtinen, P. Myllyperkiö, J. Konu and M. Haukka, ACS Omega, 2018, 3, 11558-11561.

27 S. K. Kurtz and T. T. Perry, J. Appl. Phys., 1968, 39, 3798-3813.

28 CrysAlis PRO, Agilent Technologies Ltd, Yarnton, Oxfordshire, England.

29 O. V. Dolomanov, L. J. Bourhis, R. J. Gildea, J. A. K. Howard and H. Puschmann, J. Appl. Crystallogr., 2009, 42, 339-341.

30 G. M. Sheldrick, Acta Crystallogr., Sect. C: Struct. Chem., 2015, 71, 3-8.

31 Crystal structure of compound $2 \mathbf{b}$ has been deposited to CCDC database: S. P. Kelley, K. Yang, N. Corretjer, S. Gadban, R. Glaser, M. M. Kozak and B. A. Hathaway, CSD Private Commun, 2018, CCDC 1879519.

32 M. Rawal, K. E. Garrett, L. E. Johnson, W. Kaminsky, E. Jucov, D. P. Shelton, T. Timofeeva, B. E. Eichinger, A. F. Tillack, B. H. Robinson, D. L. Elder and L. R. Dalton, J. Opt. Soc. Am. B, 2016, 33, E160.

33 W. S. Wadsworth and W. D. Emmons, J. Am. Chem. Soc., 1961, 83, 1733-1738.

34 P. Munshi, B. W. Skelton, J. J. McKinnon and M. A. Spackman, CrystEngComm, 2008, 10, 197-206.

35 S. N. Oliver, P. Pantelis and P. L. Dunn, Appl. Phys. Lett., 1990, 56, 307-309.

36 G. Marras, P. Metrangolo, F. Meyer, T. Pilati, G. Resnati and A. Vij, New J. Chem., 2006, 30, 1397.

37 M. A. Sinnwell and L. R. MacGillivray, Angew. Chem., Int. Ed., 2016, 55, 3477-3480.

38 G. W. Coates, A. R. Dunn, L. M. Henling, J. W. Ziller, E. B. Lobkovsky and R. H. Grubbs, J. Am. Chem. Soc., 1998, 120, 3641-3649.

39 Analogous disorder with detailed examination of correct space group has been reported for (trans)-4-chloro-4'-nitrostilbene: N.R. Behrnd, G. Labat, P. Venugopalan, J. Hulliger and H.-B. Bürgi, CrystEngComm, 2010, 12, 4101-4108.

40 Preliminary single-crystal and powder X-ray studies with non-centrosymmetric space group $P 1$ and some SHG activity has been reported for compound 1c: P. M. Dinakaran, G. Bhagavannarayana and S. Kalainathan, Spectrochim. Acta, Part A, 2012, 97, 995-1001; these results were subsequently challenged, $c f$. ref. 41.

41 B. R. Srinivasan, Z. Tylczynski and V. S. Nadkarni, Opt. Mater., 2013, 35, 1616-1618.

42 An analogous crystal structure of compound 1c was deposited to CCDC database during the time of writing this contribution: T. H. Chunhua, A. C. Soegiarto and M. D. Ward, CSD Private Commun., 2020, CCDC 1976072.

43 H. Gruen and H. Goerner, J. Phys. Chem., 1989, 93, 7144-7152.

44 D. Pines, E. Pines and W. Rettig, J. Phys. Chem. A, 2003, 107, 236-242.

45 T. Nakabayashi, M. Wahadoszamen and N. Ohta, J. Am. Chem. Soc., 2005, 127, 7041-7052.

46 R. Lapouyade, K. Czeschka, W. Majenz, W. Rettig, E. Gilabert and C. Rulliere, J. Phys. Chem., 1992, 96, 9643-9650.

47 D. Schulte-Frohlinde, H. Blume and H. Güsten, J. Phys. Chem., 1962, 66, 2486-2491. 